IZA DP No. 9621

The Health Implications of Social Pensions:

Evidence from China's New Rural Pension Scheme

Lingguo Cheng

Hong Liu

Ye Zhang

Zhong Zhao

January 2016 


\title{
The Health Implications of Social Pensions: Evidence from China's New Rural Pension Scheme
}

\author{
Lingguo Cheng \\ Shanghai University of Finance and Economics \\ Hong Liu \\ Central University of Finance and Economics
}

Ye Zhang

Nanjing University

Zhong Zhao

Renmin University of China and IZA

\author{
Discussion Paper No. 9621 \\ January 2016
}

IZA

P.O. Box 7240

53072 Bonn

Germany

Phone: +49-228-3894-0

Fax: +49-228-3894-180

E-mail: iza@iza.org

\begin{abstract}
Any opinions expressed here are those of the author(s) and not those of IZA. Research published in this series may include views on policy, but the institute itself takes no institutional policy positions. The IZA research network is committed to the IZA Guiding Principles of Research Integrity.

The Institute for the Study of Labor (IZA) in Bonn is a local and virtual international research center and a place of communication between science, politics and business. IZA is an independent nonprofit organization supported by Deutsche Post Foundation. The center is associated with the University of Bonn and offers a stimulating research environment through its international network, workshops and conferences, data service, project support, research visits and doctoral program. IZA engages in (i) original and internationally competitive research in all fields of labor economics, (ii) development of policy concepts, and (iii) dissemination of research results and concepts to the interested public.
\end{abstract}

IZA Discussion Papers often represent preliminary work and are circulated to encourage discussion. Citation of such a paper should account for its provisional character. A revised version may be available directly from the author. 


\section{ABSTRACT \\ The Health Implications of Social Pensions: Evidence from China's New Rural Pension Scheme*}

This paper estimates the causal effect of income on health outcomes of the elderly and investigates underlying mechanisms by exploiting an income change induced by the launch of China's New Rural Pension scheme (NRPS). Using this policy experiment, we address the endogeneity of pension income by applying a fixed-effect model with instrumental variable correction. The results reveal that pension enrollment and income from the NRPS both have had a beneficial impact on objective measures of physical health, cognitive function, and psychological well-being of the rural elderly, and also reduced mortality over a three-year horizon by 6 percentage points. Evidence further suggests that pension recipients respond to the new pension income in multiple ways: improved nutrition intake, better accessibility to health care, increased informal care, increased leisure activities, and better self-perceived relative economic situation. These in turn act as channels from pension income to health of the Chinese rural elderly.

JEL Classification: H55, I12, I38, J14

Keywords: $\quad$ pension income, health, channels, elderly, China

Corresponding author:

Hong Liu

Central University of Finance and Economics

39 Xueyuan Nan Road

Beijing 100081

China

E-mail: liuhong@cufe.edu.cn

\footnotetext{
* We would like to express appreciation for comments from participants of the $7^{\text {th }}$ International Symposium on Human Capital and Labor Markets; the Annual Conference of the Chinese Economist Society; and seminars at Peking University, Shanghai University of Finance and Economics, Central University of Finance and Economics, and Renmin University of China. This study was supported by NIH R01 (Grant No. 5R01-AG023627), the Natural Science Foundation of China (Grant No. 71110107025, No. 71203244, and No. 71233001), the National Social Science Fund of China (Grant No. 13CJY028), and the Training Program for Major Fundamental Research of Central University of Finance and Economics (Grant No. 14ZZD001).
} 


\section{Introduction}

Population aging presents one of the greatest challenges for developing countries to ensure the well-being of their growing number of old people. Social pension programs have been widely regarded and implemented as an important policy device to provide income security for old people. Recently many developing countries such as Brazil, South Africa, Mexico, and China have initiated government transfer or social pension programs for the uncovered elderly, which may have important implications for the health and well-being of these new pension recipients (Jung and Tran, 2012).

The positive association between income and health is well established in the literature, based on empirical evidence across countries and in different time periods (van Doorslaer et al., 1997; Zimmer and Amornsirisomboon, 2001; Gerdtham and Johannesson, 2004; Smith and Goldman, 2007; Smith, 2007). However, there remain crucial open questions that deserve further investigation, such as whether the association reflects causality from income to health and what mechanisms underlie the effects of income on health (Deaton and Paxson, 1998; Smith, 1999). The main empirical challenge in establishing causality from income to health is to correct the possible estimation bias caused by reverse causality. The reverse causality can be due to contemporary factors. For example, more healthy people may also have higher earning capacity. It can also be due to life-cycle factors. ${ }^{1}$ The possibility that the correlation between current health and current income at old ages is partly driven by health shocks at earlier ages complicates the estimation of causal effects of income on health, and may bias welfare analysis based on association between income and health (Smith, 1998; Richter, 2006). The above life-cycle factors also imply that the causality between income and health may vary considerably with age (Cutler et al., 2008; Smith, 2007).

A number of empirical studies have attempted to identify the causal effects of income and wealth on health, using exogenous income shocks or sophisticated panel

\footnotetext{
1 For example, current income (including pension income) of the elderly depends on cumulative work histories, which may be influenced by their past health conditions. In addition, current health and past health are highly correlated.
} 
data models, but they have produced mixed results. For example, Ettner (1996) finds a large positive effect of income on physical and mental health for United States adults, by applying an instrumental variable approach. ${ }^{2}$ Frijters et al. (2005) find that the positive effect of income changes on health is statistically significant but economically small in magnitude, based on a panel data of East and West Germans in the years following the German reunification. Using lottery prizes as an exogenous source of income variation, Lindahl (2005) show that higher incomes lead to better health for the full sample of the lottery players aged $34-76$, but the income effect is not significant for those aged 60 and above. Consistent with Frijters et al. (2005) and Lindahl (2005), several recent studies on the United States find a small positive effect of wealth on health for the full sample (Meer et al., 2003), but no effect for couples aged 51-61 (Michaud and van Soest, 2008), or for the elderly aged 70 and above (Adams et al., 2003). As the above empirical studies all focus on wealthy and industrialized nations, the finding of no income gradient of elderly health is not particularly surprising, given universal biological frailty, good public health insurance, and well-functioning social security systems in those countries (Kim and Durden, 2007; Wilkinson and Pickett, 2006). However, contradicting the main findings in the literature, Snyder and Evan (2006) show that the American elderly who received less income in social security benefits had significantly lower mortality than those with higher earnings. ${ }^{3}$

As transition and developing countries usually provide limited social safety nets, income should be more important for health production, particularly for the elderly population, who are vulnerable to economic and health risks. The income-health gradient and its underlying mechanisms in these counties deserve special attention. Among the few recent studies, Case (2004) shows that exogenous increases in pension income have improved the health status of pensioners and other household members in

\footnotetext{
${ }^{2}$ Ettner (1996) uses the state unemployment rate, work experience, parental background, and spouse characteristics as instruments for family income. However, the exogeneity of these instruments has often been questioned (Meer et al., 2003; Frijters et al., 2005).

${ }^{3}$ Snyder and Evan (2006) suggest that those elderly with lower income have engaged in more post-retirement part-time work, which may have prevented social isolation, and thus reduced mortality.
} 
households that pool income in South Africa. Two studies on Russia by Jensen and Richter (2003) and Richter (2006) have found adverse effects of exogenous negative income shocks. The first one finds that the pension loss, associated with the Russian pension crisis, has led to worsened health and higher mortality rate among the pensioners. Similarly, the second one shows that during the wage arrears crisis in Russia, the loss in household wage income had detrimental effects on health outcomes of the elderly. Those studies have considered several pathways such as nutrition, health care accessibility, and health behavior. However, there are additional channels that deserve further investigation. Moreover, the underlying causal mechanisms may vary across countries, due to different economic development stages, social welfare systems, and cultural contexts.

The first contribution of this paper is to identify and estimate the causal effect of income on health outcomes of the elderly in China, a middle-income developing country, by using an income change induced by China's New Rural Pension Scheme (NRPS). As one of the pillars of China's social security system, the NRPS is a public pension program for the rural population that was established in 2009 and expanded gradually to nearly all counties by the end of 2012. At the time of introduction, individuals aged 60 years and above were eligible for a basic monthly pension that varied across regions, but the amount of the pension was uncorrelated with observed or unobserved individual characteristics, such as current or past labor supply behavior. Taking advantage of this unique policy experiment, we identify the causal effect of income on health by exploiting exogenous time variation in the NRPS implementation at the county level through an instrumental variable approach.

The second contribution of this paper is to study multiple health outcomes. Our analysis draws on panel data from the Chinese Longitudinal Healthy Longevity Survey. That is a longitudinal survey project in operation since 1998, mainly focusing on the elderly population, and covers a rich set of well-being and health outcomes. Johnston et al. (2009) suggest that using commonly available self-reported measures of health may lead to underestimation of the income-health gradient, because reporting error is related to income. Our data set allows us to examine not only self-reported health 
measures, but also objective measures of health, cognitive function, psychological wellbeing, and mortality.

The rich information in the data also allows us to explore more thoroughly how income affects different health outcomes through a variety of important potential channels, such as food consumption, health behavior, perceived access to medical care, informal care service, labor supply, leisure activity, and perceived relative economic status. We also examine the relative importance of those channels. This is our third contribution.

The last contribution of our study is to add to the limited literature on the evaluation of social pension programs in developing and transition countries (Kakwani and Kalanidhi, 2005; Palacios and Oleksiy, 2006; Barrientos, 2009). As one of the few studies to evaluate the impact of the NRPS, this paper not only shows evidence that the NRPS has improved the well-being of the elderly, but also provides a useful set of health-related results for evaluating the effects of other government interventions on health outcomes. As China has a large number of elderly people, our results have important implications for the further comparison of health benefits of the social pension program and other government programs such as public health insurance. Given the rapid aging of the population around the world and the limited social safety net in developing countries, our findings may be of great significance for other countries as well.

The rest of the paper is structured as follows. Section 2 provides background on China's rural pension system. Section 3 describes the data and main variables. Section 4 outlines our empirical framework, and Section 5 gives our main results, with discussions on identification issues and potential objections to our findings. Section 6 investigates how pension income affects the health of the elderly, and Section 7 provides heterogeneous analysis for different subsamples. Section 8 concludes the paper. 


\section{China's Rural Pension System}

The old age pension in China has comprised two separate systems for urban and rural residents. With the establishment of the People's Republic of China in 1949, China's first formal pension system - an enterprise-based, pay-as-you-go benefit scheme - was introduced in 1951 for state employees, civilian and military. At this time, rural people had to depend on the low-level rural economic collective system for employment and income, and old age support was jointly provided by the collective (at the village level) and the family.

In line with the market-oriented reform starting in 1978, the urban old-age pension system was reformed and extended to cover the private sector in the 1990s. In the meantime, the transition from the collective commune system to the "household responsibility system" dismantled the institutional basis for collective-based old age security system in rural China. Rural people had to rely mainly on their own families for old-age support (Shi, 2006). In 1986, the government initiated some pilot projects for reestablishing a rural pension scheme, starting with well-off counties. These projects placed most financial responsibility on individuals, supplemented by the local collectives, and that led to a very low take-up rate. Despite significant expansion of the geographical coverage of these pilots in the 1990s, there were wide concerns about their financial sustainability and effectiveness. The government ceased the expansion of the pilot schemes in 1998, and their coverage shrank rapidly. According to the 2000 census, less than 5 percent of the rural elderly aged 60 and above had pension benefits, about 43 percent still had to work, and 48 percent depended on family support (Wang, 2006).

To promote the economic well-being of rural residents, the government launched a brand new nationwide pension project known as the New Rural Pension Scheme in rural China in 2009. It was first implemented in 320 pilot rural counties, and was expanded to 838 counties in 2010 , to 1,914 counties in 2011 , and to nearly all 2,853 rural counties by 2012. According to China Statistical Yearbook 2012, there were 326.4 million rural residents participating in this scheme, accounting for nearly one-quarter of the total population, and there were 89.2 million pension beneficiaries in 2011 . 
----Insert Figure 1 here----

The NRPS is composed of two components - the social pension part and the contributory pension part - to provide minimum income protection in old age as well as some saving incentives. As the individuals in our study sample are mainly subject to the noncontributory component, we focus on the key features of the social pension part, and briefly introduce the contributory pension part of the scheme. ${ }^{4}$

Following the broad guideline issued by the central government, the program operates at the county level. Local rural residents aged 16 and above are eligible to participate if they are not in school or not covered by the basic urban pension scheme. Participation is voluntary. Participants who have contributed for 15 years will be eligible for a flat rate pension at age 60 , which consists of a noncontributory basic pension and a monthly payment from the individual account. In this initial stage, people aged 60 and over are eligible to directly receive the basic pension benefit, as long as their children contribute to the scheme. ${ }^{5}$ In some counties those aged 60 and over are also allowed to make up the shortfall on vesting contributions in a lump sum, which may or may not be subsidized, depending on local policies, so that they can receive higher pension payments.

Different from the old pilot schemes, financing of the NRPS is heavily subsidized by the government. The central government funds the whole noncontributory basic pension for the relatively poor central and western regions, and half their cost for eastern regions. Local governments are encouraged to supplement the basic pension benefit at their discretion from their own revenues. Participating individuals are required to contribute 100 to 500 Chinese yuan annually to individual pension accounts, which is partially matched by local government in the amount of at least 30 Chinese yuan per year regardless of the level of individual contribution. ${ }^{6}$

\footnotetext{
${ }^{4}$ The detailed description of the design of the contributory pension part can be found in Cai et al. (2012).

${ }^{5}$ In practice, many counties have gradually dropped this family-binding eligibility requirement.

${ }^{6} 1$ US dollar is about 6.2 Chinese yuan.
} 
The minimum basic pension benefit was 55 Chinese yuan per month initially, and increased to 70 Chinese yuan in 2014, in accordance with the GDP growth and inflation. The amount of the basic pension varies considerably across counties; it was as high as about 360 Chinese yuan per month in some developed areas such as Beijing and Shanghai in 2012, but was only 55 Chinese yuan per month in some less developed areas. In some regions, such as Chongqing and Shanxi province, the elderly aged 70 and over also receive an additional monthly subsidy of 10-20 Chinese yuan on top of their basic benefit.

The average level of the basic pension was 78.6 Chinese yuan (12.7 US\$) per person per month in March 2013. ${ }^{7}$ This amount is approximately 12 percent of the average per capita net income $(7,916 \text { Chinese yuan })^{8}$ and 17 percent of the average per capita living expenses among Chinese rural households (5,415 Chinese yuan) in 2012, and equals 41 percent of China's latest official rural poverty line. ${ }^{9}$ Therefore, the basic pension benefit of the NRPS is still far from ensuring a minimum living standard for the elderly, but it can help them to pay for basic subsistence.

\section{Data and Variables}

The data in this study are from the Chinese Longitudinal Healthy Longevity Survey (CLHLS), which has been conducted by the Center for Healthy Aging and Development Studies at Peking University in China and co-sponsored by the National Institute on Aging in the United States. It provides extensive information on the health status and quality of life of the elderly population aged 60 and above in China. The survey covers 22 out of 34 provinces, including 10 eastern, 8 central, and 4 western

\footnotetext{
7 The data come from the government report available online: http://www.mohrss.gov.cn/ncshbxs/NCSHBXSgongzuodongtai/201305/t20130531_104217.ht $\mathrm{m}$

${ }^{8}$ The replacement rate from the noncontributory social pension of the NRPS was at the low end of the range for the OECD countries, with a cross-country average of around 30 percent of average earnings (Cai et al., 2012).

9 In 2011, the Chinese government raised the poverty line from 1,274 Chinese yuan per year in 2010 to 2,300 Chinese yuan (370 US\$) per year, which is higher than the international poverty line of $\$ 1.90$ a day in 2011 purchasing-power parity.
} 
provinces, which host approximately 85 percent of the total population in China. Half of the counties and cities in each sample province were randomly selected to be included in the survey. The CLHLS primarily focused on the oldest-old population aged 80 and above in the first two waves, i.e., wave 1998 and wave 2000, and was expanded to cover the elderly aged 60 and above in follow-up waves conducted in 2000, 2002, $2005,2008 / 09,2011 / 12$, and $2014 .{ }^{10}$ For the purpose of this analysis, we mainly use the 2008/09 and 2011/12 waves of CLHLS data, i.e., one wave before and one wave after the introduction of the NRPS in 2009.

\subsection{Health Outcomes}

As the CLHLS consists of an in-home interview and a basic physical examination, the data set offers multiple health outcome measures, including physical health, cognitive function, psychological health, and mortality, with good quality.

First, we have four types of physical health measures: self-assessed general health, limitations on the physical ability to perform instrumental activities of daily living (IADL), and measured hypertension and height. We measure self-assessed general health according to a five-category survey question, "How do you rate your health at present?" and code a dummy health indicator as 1 if the respondent reports "excellent" or "good" and 0 otherwise.

The CLHLS contains an assessment of an individual's physical ability to perform IADL. The survey instrument was based on international standard questionnaires and modified to fit into the Chinese culture and social context with extensive pilot testing (Zeng et al., 2002). The IADL measure is a binary indicator taking on a value of 1 if a respondent reports that he or she can finish eight daily activities without assistance, including visiting the neighbors, doing shopping, cooking a meal, washing clothes, walking continuously for 1 kilometer, lifting a weight of 5 kilograms, continuously crouching and standing up three times, and taking public transportation.

\footnotetext{
10 The most recent wave of the CLHLS data was collected in 2014 and is not available at present, so we are not able to include the 2014 wave in the main analysis.
} 
Johnston et al. (2009) show that the income-health gradient may be underestimated using self-reported health measures because of reporting error. The strength of our data set is that, in addition to the above two self-reported measures, we have two objective health measures: hypertension and height, measured by the medical personnel during the face-to-face interviews in each wave.

Following the medical standard, we use the average of the two blood pressure readings taken in the interview, and define respondents as having hypertension if their systolic blood pressure is higher than $140 \mathrm{mmHg}$ or diastolic pressure is higher than 90 $\mathrm{mmHg}$.

Although adult height is widely considered as a health indicator, most elderly persons experience shrinkage in height as a consequence of aging. Huang et al. (2013) show that height shrinkage is an important marker of later-life health and it is positively correlated with the deterioration of a variety of health outcomes. The CLHLS has height measurements in the 2008/09 and 2011/12 waves; the estimated height shrinkage of a respondent from the models can be interpreted as the impact of the NRPS on one dimension of objective health measurements of the elderly.

Second, following the wide practice in the literature (Crum et al., 1993; Folstein et al., 1975), we use the Mini-Mental State Examination (MMSE) to measure five areas of cognitive function of the elderly: orientation, reaction, calculation, recall, and language. It is a 24-question measure with a total score ranging from 0 to 30 . As an alternative we construct an indicator of whether the respondent has a MMSE score more than 24, suggested in the literature as indicating no cognitive impairment (Folstein et al., 1975). There are few studies on the effect of income on cognitive function of the elderly in the literature (Case, 2004; Jensen and Richter, 2003; Richter, 2006). Given the importance of cognitive function as a dimension of quality of life, our study provides new insight into this important yet underresearched area.

Third, psychological well-being of the respondent is measured using an index of depression consisting of six items: (1) "Do you always look on the bright side of things?" (2) "Do you often feel fearful or anxious?" (3) "Do you often feel lonely and isolated?" (4) "Do you feel that the older you get, the more useless you are?" (5) "Are you as 
happy as when you were younger?" (6) "How do you rate your life at present?" Although we have less depression-related items here, the individual questionnaire items are virtually identical to those used in standard psychological health measures in the literature (Gardner and Oswald, 2004; 2007; Proper et al., 2005). Following the literature, we use the sum of all the responses as a measure of mental well-being, where the response to each question ranges from 0 to 3, and higher scores indicate lower wellbeing. According to Gardner and Oswald (2007), the typical score for healthy individuals is around 5-6.5 for our 18-point Likert scale.

Last, we treat mortality as one type of health outcomes, and construct an indicator measuring whether the respondent died by the time of a follow-up survey. In the CLHLS, mortality information for the respondents who died between survey intervals was gathered in interviews with a close family member of the deceased.

\subsection{Sample Definition and Description}

We restrict the study sample to the rural elderly, and exclude about 15 percent of the observations with missing information or having other pensions than the NRPS. ${ }^{11}$ Out of the 8,683 rural elderly interviewed in wave $2008 / 09,4,153$ remained in the 2011/12 survey, 3,362 (38.7\%) died before wave 2011/12, and 1,168 (13.5\%) were lost to follow-up. The issue of panel attrition will be addressed in a later subsection. Our main study sample is a panel composing of 4,153 elderly individuals who were in the survey in both waves. ${ }^{12}$ When mortality is used as a health outcome, we also include the deceased sample.

In each wave, the respondents were asked whether they were covered by a retirement pension, social pension, or private pension. As the NRPS was the only social pension initiated in rural China since 2009 and has been expanded gradually to all rural areas, those respondents who reported no social pension in wave 2008/09 but having a social pension in wave 2011/12 are considered as the NRPS pensioners. Those who

\footnotetext{
11 The other types of pension include retirement pension, private or commercial old age insurance, the old rural pension that started before 2009, etc.

${ }^{12}$ Since all the observations in our study sample are aged 60 and above, the NRPS enrollees are the same as the NRPS recipients in this paper.
} 
have had no social pension during the study period are taken as the control group. In wave 2011/12, 907 respondents (about 22 percent) enrolled in the NRPS, and received an average monthly pension income of 92 Chinese yuan.

Table 1 presents descriptive statistics of health and economic status separately for pensioners and non-pensioners with the $t$-test indicating the significance level of pairwise comparisons of the two groups before and after implementation of the NRPS, respectively. The last column presents the simple difference-in-differences results, which compare the difference between pensioners and non-pensioners in wave 2011/12 with the corresponding difference in wave 2008/09. Prior to the NRPS, the pensioners were statistically similar to the non-pensioners with regard to baseline IADL, measured height, and cognitive function, but healthier in terms of self-reported general health and depression, and had a higher rate of hypertension than the non-pensioners. After controlling for baseline health conditions, the simple difference-in-differences analysis shows that the pensioners are $10 \%$ less likely to have hypertension, are about $1.37 \mathrm{~cm}$ taller, but are 5\% less likely to report good overall health, and have higher self-reported depression index.

\section{-------Insert Table 1 here-------}

The last three rows of Table 1 show that total annual household income has increased by 8,092 yuan for the pensioners and by 6,497 yuan for the non-pensioners, leading to a net increase of 1,595 yuan for the pensioners between these two waves; ${ }^{13}$ this suggests that the effect of the NRPS on household income is positive though insignificant. Similarly, although poverty rates were lower among pensioners before and after the NRPS, the difference-in-differences is -0.018 and statistically insignificant. Thus, overall the descriptive statistics suggest that enrollment in the NRPS has only a modest effect on the economic status of the pensioners, which may be expected in view of the low level of the NRPS benefits; however, in the following analysis we will show that such a modest income increase can result in significant improvements in health outcomes of the elderly.

${ }^{13}$ All incomes are inflated to year-2011 Chinese yuan. 
To understand the health effects of the NRPS, we consider several channels through which pension income may affect health of the elderly. First, we create several indicators measuring food consumption of the respondent, including whether the respondent has sufficient financial support for daily expenses, and whether the respondent frequently consumes high-protein foods (such as meat, fish, and eggs) or high-vitamin foods (fruits and vegetables). Second, we have two indicator variables measuring smoking and drinking behavior of the respondent, because tobacco and alcohol may be normal goods, and an increase in income may also induce more smoking or drinking among the elderly. Third, there are a set of variables capturing informal care service and perceived access to medical care for the respondent. We have one variable measuring hours of informal care received from the respondent's children and grandchildren and their spouses in the previous week, which includes help with bathing, dressing, toileting, indoor movement, continence, and eating. Based on the responses to the related survey questions, we also construct four indicators for whether the elderly person has someone to talk with in daily life, can get help when having problems or difficulties, can get adequate medical care when sick, and has failed to get necessary care due to costs.

We have several measures for leisure activity and labor supply of the elderly person. Labor supply of the elderly is measured by two binary variables, one indicating formal labor force participation - i.e., whether the respondent is still working in the formal workforce (including both on-farm and off-farm work) at the survey time - and another indicating informal work, including doing household chores or taking care of grandchildren every day. The respondents were asked about their participation in leisure activities such as planting flowers or raising pets, reading newspaper or books, watching TV or listening to radio, playing cards or mah-jong, and participating in organized social activities. The sum of the responses is used as a leisure index, which ranges from 0 to 5 .

In addition, we construct a binary variable measuring the self-perceived relative economic status of the elderly person, which equals one if the respondent rated his/her economic status as very rich or rich when compared to others in the local area, and zero 
otherwise. To measure the pension recipient's power within the household, we create another binary variable indicating whether the respondent can make decisions on some of the main spending in the household.

Summary statistics for the above channel variables and covariates of interest are reported in Table 2. In comparison with non-pensioners, the pensioners were more likely to have someone to talk with, be able to get help when having problems, and have sufficient medical care when sick; they had more leisure and reported better relative economic status and more involvement in household decision-making on spending after the reform, although the two groups did not differ in these characteristics in the baseline data.

\section{------Insert Table 2 here-------}

Other variables used as controls in our estimations include age, gender, marital status, ethnicity (Han or ethnic minorities), years of schooling, having a white-collar (professional, managerial, or administrative) job before age 60 or not, number of living children, household size, home ownership, and health insurance status. As shown in Table 2, at baseline the pensioners had more living children and were more likely to have health insurance, but the simple difference-in-differences values are both statistically insignificant.

\section{Main Empirical Method}

To estimate the effects of pension enrollment and income on health outcomes, one simple reduced-form strategy would be to compare the health changes of pensioners and non-pensioners before and after the implementation of the NPRS. Given the data we have, we first specify the following fixed effect (FE) model:

$$
Y_{i t}=\beta_{0}+\beta_{1} N R P S_{i t}+\beta_{2} X_{i t}+\beta_{3} v_{t}+c_{i}+\varepsilon_{i t}
$$

where the subscripts $i$ and $t$ represent individuals and waves. $Y_{i t}$ is a set of health outcome variables that have been defined in the previous section. NRPS $S_{i t}$ represents our key independent variable, the NRPS enrollment status or income from the NRPS, 
depending on the model specification; and its coefficient $\beta_{1}$ is the parameter of interest, which captures the effect of pension enrollment or pension income on health outcomes of the elderly. The vector $X$ includes a rich set of individual and household characteristics such as age, marital status, household size, number of adult children, and health insurance coverage. $v_{t}$ is the wave effect and $c_{i}$ is the individual fixed effect.

Under the NRPS, the elderly aged 60 and above are allowed to directly receive basic pension benefits without contributing, conditional on the enrollment of their adult children (this condition was dropped later), or receive higher pension payments by making a lump sum contribution to cover the shortfalls in vesting contributions (in some places). As we use a sample of individuals aged 60 and above, their decisions of pension enrollment and pension benefits are unlikely to be affected by the life-cycle factors discussed before, but a simple comparison of the pensioners with the non-pensioners still raises concern due to the voluntary nature of the NRPS. Taking up the pension may be an endogenous household decision. For example, elderly persons experiencing a negative financial shock such as the one caused by a recent illness may be more willing to take up the NRPS benefits. In this case, the OLS estimator of the health benefits of the NRPS is downward biased. If elderly persons with a longer life expectancy may expect more benefits from the NRPS and thus be more likely to participate, the bias will be in the other direction. Thus, the overall direction of the selection bias is ambiguous.

To address the above concern, besides controlling for the observed variables, our FE model includes individual fixed effects $c_{i}$, which not only help address endogenous selection into the NRPS, but also correct for time-invariant sources of attrition bias. In the model, we also control for the wave effect $v_{t}$, which represents the common timeseries changes in health outcomes for pensioners and non-pensioners. However, the FE model cannot correct for the bias resulting from the unobserved factors that were timevariant. If these factors are correlated with both the NRPS status and income and the health outcomes of the elderly, the FE estimate of the coefficient $\beta_{1}$ will still suffer from selection bias (e.g., Heckman, 1990). We rely on an instrumental variable (IV) approach to purge this bias, so our main empirical approach is a fixed effect model with 
instrumental variable correction (FE-IV).

For identification of the FE-IV model, we exploit the timeline of the implementation and expansion of the NRPS at county level to generate a valid instrument for individual pension status and income. As shown in Figure 1, China started the NRPS in about 11 percent of rural counties in 2009, and gradually expanded its coverage to nationwide by the end of $2012 .{ }^{14}$ As the NRPS operates at the county level, rural elderly with a local household registration permit (hukou) but no urban public pensions are eligible for the local NRPS. For the study sample of individuals aged 60 and above from wave 2008/09 to wave 2011/12, the major eligibility requirement for NRPS participation is the implementation of the program in that county. Simply speaking, the elderly with a local hukou in the project counties were eligible for the NRPS, whereas the elderly without a local hukou in the project counties were not. However, when a county implemented the NRPS was mainly decided by central and provincial governments. Even though a county might be able to influence the decision of the upper-level governments to some degree, the timing of implementation of the NRPS is still exogenous to households and individuals.

According to the lists of the NRPS pilot counties authorized by China's central and provincial governments, we are able to determine when each sample county started the NRPS. We generate a continuous variable measuring the program implementation duration at time of survey, by subtracting each county's date of program initiation from the interview date of each respondent. It is coded as 0 if the respondent was interviewed before the introduction of the NPRS in the county. The identification strategy crucially hinges on the assumption that the instrumental variable only affects health outcomes through individual enrollment into the NRPS or pension income from the NRPS. We defer examining and discussing the validity of our IV to Section 5.2.

${ }^{14}$ In our CLHLS sample, out of 535 surveyed counties, the NRPS covered 77 (14 percent) in 2009, 204 (38 percent) in 2010, and almost all counties in late 2011 or early 2012. This suggests that our sample has a similar timing pattern of county-level NRPS implementation to that of the official statistics. 


\section{The Health Implications of the NRPS}

\subsection{Main Results}

This subsection presents the main empirical results of the paper. As discuss before, we examine a host of health outcomes: self-assessed general health, IADL limitation, measured hypertension, measured height, MMSE score, cognitive status, and depression index. We report three sets of results for each health outcome, from OLS, FE, and FE-IV, respectively. Columns $1-3$ of Table 3 show the coefficients on the NPRS take-up, and columns 4-6 the coefficients on the log income from the NPRS. For simplicity, we exclude the coefficients of non-key variables from the main tables except in Appendix Table A2, where we report the coefficients for all explanatory variables from the FE-IV estimations. ${ }^{15}$

------Insert Table 3 here-------

Generally speaking, the signs of the estimated coefficients on pension status and pension income from OLS, FE, and FE-IV are consistent with each other, with few exceptions, and the FE-IV estimates are larger in magnitude than the OLS and FE estimates. We focus our discussion primarily on the results from the FE-IV estimations, which use the time variation of the implementation of the NRPS at county level as the IV.

For physical health outcomes, the FE-IV results show that the take-up of the NRPS has no significant effect on self-rated general health of the elderly, but improves their IADL performance by 11 percentage points. The pension enrollment has also significantly reduced the incidences of hypertension by 21 percentage points. Its impact on measured height is positive and significant; as we control for height before the NRPS, the FE-IV estimate suggests that the pensioners have experienced $3.5 \mathrm{~cm}$ less height shrinkage than the non-pensioners. ${ }^{16}$ Overall, the NRPS has a positive effect

\footnotetext{
15 We defer discussing the coefficients of other explanatory variables until Section 7, where we carry out a heterogeneous analysis along multiple important dimensions such as gender, age, living arrangement, and income, and highlight the role of some key variables.

${ }^{16}$ Our $3.5 \mathrm{~cm}$ height shrinkage estimate is comparable to the ones in Huang et al. (2013), who show that the average estimated height shrinkage is $3.3 \mathrm{~cm}$ for males and $3.8 \mathrm{~cm}$ for females with a standard deviation of $5 \mathrm{~cm}$ among the elderly aged 60 and above in China. Moreover, in
} 
on objective measures of physical health of the elderly.

The NRPS take-up also positively affects cognitive functions of the elderly. Specifically, the pension enrollment has significantly improved the MMSE score by more than 2 points (a nontrivial effect given that the average MMSE score is 22 with a standard deviation of about 9), and increased the probability of good cognitive function by 18 percentage points. Finally, in the FE-IV specification, we find that the coefficient on the NRPS take-up is negative and statistically significant for depression index. This suggests that the NRPS has improved the psychological well-being of the pensioners.

We now turn to examine the effects of pension income on health outcomes of the elderly, and the key independent variable is the log income from the NRPS (see columns 4 to 6). Again, the income from the NRPS has significant positive effects on a host of health outcomes of the pensioners, except self-reported general health. A 100-percent increase in pension income has significantly improved the likelihood of performing IADL by 2.4 percentage points, lowered the probability of experiencing hypertension by 5.4 percentage points, and reduced height loss by $0.8 \mathrm{~cm}$. Moreover, a 100-percent rise in the NRPS benefits leads to a 0.57-point increase in MMSE score, 4.2 percentage points more pensioners having good cognitive function, and a 0.30-point decrease in depression index.

As a whole, our main results show that both pension enrollment and income from the NRPS have improved the physical health, psychological well-being, and cognitive function of the elderly.

\subsection{Validity of Our Instrumental Variable}

In this subsection, we address several concerns about our instrumental variable. As discussed in Section 4, since the NRPS is a voluntary program, the pensioners may differ from the non-pensioners in unobserved individual factors correlated with their health. We deal with this selection bias by using the FE-IV approach to control for selection into the NRPS on unobservables.

Section 7 we find that the NRPS has reduced height shrinkage more for the pensioners aged 85 and above than for those under age 85 . 
One concern is that the IV is not strongly correlated with individual pension status or pension income. We can test this directly from the data. The bottom part of Table 3 shows that the NRPS duration at the county level is strongly positively correlated with individual pension status and with the income from the NRPS. The $F$-statistics from the first stages are 780 and 757, respectively; both are well above the usual threshold value for weak-strong identification in the IV literature.

As we restrict the sample to the rural elderly with no pension in the baseline period, they would be eligible for the local NRPS if the program had been introduced in their county of residence. Another concern is whether the elderly can migrate to other counties to enroll in the NRPS. If so, then this will invalidate our instrument based on the duration variation of the NRPS implementation at the county level. Under the NRPS, an elderly person can hardly migrate from a non-NRPS county to a NRPS county to obtain pension benefits without changing his/her hukou. According to current Chinese hukou policy, it is generally difficult to change the hukou location across counties, and even harder for the elderly, since they are unlikely to change their hukou through marriage migration or going to college, the two main channels for hukou mobility in China.

The identification assumption of our IV approach also rules out any other unobserved county-level differences that are associated with the timing of county-level NRPS implementation as well as with health outcomes of the elderly, after controlling for individual pension status and income, other regressors, and time-invariant unobservables. In order to gauge the validity of this assumption, we apply two placebo tests in Table 4.

\section{------Insert Table 4 here-------}

The results in column 1 are the intention-to-treat (ITT) estimates of treatment effects for our main sample, i.e., the rural elderly with no pension in the baseline period. In the fixed-effect specification, the estimates on program duration of the NRPS in the county broadly agree with our main estimates on individual pension status in Table 3 , and provide a conservative estimate for the effect of treatment. 
In the first placebo test, instead of using the main sample, we use the sample of rural elderly with retired pension during our study period from wave 2008/09 to wave 2011/12, and apply OLS and FE to the new data in a specification similar to that in column 1. The rationale for this test is that those retired pensioners are not eligible for the NRPS, but reside within the same rural areas as the eligible elderly. If the abovementioned county-level unobserved factors (e.g., pilots of home-based elder care services) were the driven force behind our main results, we could also obtain similar results for the ineligible pensioners, since the same county-level unobservables also affect their health outcomes. Columns 2 and 3 present the results for this placebo test, and all of them are insignificant.

Another possible threat to the validity of the identification strategy is that our results are driven by different patterns of health dynamics between the rural elderly in the NRPS and non-NRPS regions, which can be caused by different rural health insurance policies for different counties. For example, the New Cooperative Medical Scheme (NCMS) was first introduced in 2003, and expanded to nearly all counties by 2008. If the duration of the NCMS was correlated with the starting time of the NRPS due to unobserved county-specific factors, then it would be possible that the NRPS and non-NRPS regions had different health dynamics. ${ }^{17}$ To check how important this threat is, we limit the analysis to those who have also been observed in wave 2005 , and estimate a "false experiment" specification in which the NRPS has not started yet. If, in the absence of the program, the rural elderly in the NRPS regions were on different health tracks from those in non-NRPS regions due to unobserved regional characteristics, such difference would very likely have existed before the launch of the NRPS. The results in columns 4 and 5 show that almost all the OLS estimates based on 2008/09 data and the FE estimates based on the panel 2005-2008/09 are insignificant. This suggests that this threat is not important.

\footnotetext{
${ }^{17}$ In our empirical study, we also control for the time-invariant characteristics of the NCMS in our FE specification based on panels 2008/09-2011/12.
} 
The above checks provide supportive evidence in favor of our identification strategy. However, we acknowledge that the exogenous assumption of an IV is inherently untestable, and we cannot definitively rule out the possibility that countylevel NRPS duration could have some other health effects beyond the one working through pension income, though we believe that these other effects are likely to be minor.

\subsection{Mortality and Sample Selection.}

One more threat to our main results may come from potential bias related to mortality and sample attrition. In our data, mortality and attrition rates during the survey interval (i.e., waves 2008/09 and 2011/12) are substantial: $38.7 \%$ and 13.5\%, respectively. The specific question is whether our main results on health benefits of the NRPS might be due to specific features (e.g., attrition) of our sample.

Mortality itself is an important health outcome. If the NRPS enrollees have higher (lower) mortality rates than non-enrollees during the study period, our main results on the health outcomes of the survivors may be overestimated (underestimated). We investigate this issue in two ways.

First, we explore the impact of the NRPS on pensioners' mortality, using the sample from the 2011/12 wave. ${ }^{18}$ Although the 2014 wave of CLHLS data has not been released yet, we have access to the information whether the respondents surveyed in wave 2011/12 died prior to wave 2014, which can be regarded as a long-run posttreatment health outcome. Table 5 reports the estimates from probit and instrumental variable probit (IV probit) models that regress mortality status in wave 2014 on NRPS status and income and other covariates in wave 2011/12, including baseline health status measures such as IADL and MMSE score. Although the probit estimates are insignificant, the IV estimates using the county-level program duration as the instrument are negative and significant at the $10 \%$ level. The IV estimates show that the NRPS has reduced the 3-year mortality rate for the pensioners by 6.1 percentage

\footnotetext{
18 Similar to our main analysis, we restrict the sample to the rural elderly without any non-NRPS pension.
} 
points; and a 100\% increase in NRPS benefits reduces the 3-year mortality rate by 1.4 percentage points. This finding is consistent with our main result in Table 3 that the NPRS has significant health benefits for the pensioners.

------Insert Table 5 here-------

Second, we estimate the ITT effect of the NRPS on mortality using a differencein-differences (DID) approach based on the pooled sample from waves 2005, 2008/09, and $2011 / 12$. The dependent variable is whether the respondent died by the time of a follow-up survey. In the DID specification, we use the NRPS target sample (i.e., the rural elderly without any non-NRPS pension) as the treated group, and use the retired pensioners from the same regions (i.e., those rural elderly who are ineligible for the NRPS) as the control group. In Table 6, the coefficient on interaction between wave 2011/12 and treatment status is negative and significant (at the 10\% level); the NRPS has reduced mortality among target elderly persons during the survey interval 2011/122014 compared to $2005-2008 / 09$ (i.e., the pre-policy mortality), relative to the mortality trend for the retired sample over this period. Moreover, serving as a placebo test, the interaction between wave 2008/09 and treatment status has an insignificant coefficient; in contrast to the change for the retired sample, mortality among the target sample did not differ between the survey intervals 2008/09-2011/12 and 2005-2008/09. This suggests that the NRPS has an insignificant effect on mortality in the short run, but may reduce mortality over a three-year horizon through health improvements of the pensioners. .

\section{------Insert Table 6 here-------}

Overall, Tables 5 and 6 provide more evidence for the long-run effects of the NPRS on mortality of the rural elderly, which is consistent with the negative long-run association between income and mortality documented in the literature (see, e.g., Smith, 1999; Deaton, 2003; Gerdtham and Johannesson, 2004). It also helps rule out the possibility that the NRPS enrollees had higher mortality rates than non-enrollees during the study period 2008/09-2011/12. Thus, our main results can hardly be overestimated. Even if mortality bias existed due to the lower mortality among the NPRS enrollees, this bias would mean that our main results are underestimated. 
Loss to follow-up is another important question concerning sample selection. As shown in Appendix Table A3, respondents with worse self-reported health, higher depression index, less health insurance coverage, and smaller household size were particularly likely to be lost to follow-up. Nevertheless, our empirical method controls for individual fixed effects that are able to correct for time-invariant sources of attrition bias. As a further check for nonrandom nonresponse, we test for attrition on timevariant observables following the approach in Becketti et al. (1988) and Ding and Lehrer (2010). Specifically, we regress the baseline health outcomes on baseline individual characteristics and their interactions with an indicator for attrition (i.e., loss to follow-up), using the full sample of wave 2008/09. In Appendix Table A4, the coefficients on the attrition indicator suggest that there is no significant difference in most baseline health outcomes between subsequent attritors and non-attritors, after controlling for demographic and socioeconomic covariates. In the bottom part of Table A4, the F-tests of the joint significance of the attrition indicator and its interaction terms with time-varying observables are decisively rejected at conventional significant levels. This implies that those lost to follow-up do not differ systematically from those in the follow-up sample or known to be deceased, ${ }^{19}$ and the attrition bias due to loss to follow-up is not serious. ${ }^{20}$

\section{How the NRPS Affects Health of the Elderly}

Given our main findings that the NRPS status and income both have important health benefits for the elderly, we further examine multiple transmission channels from the NRPS to health outcomes of the elderly.

\footnotetext{
${ }^{19}$ Using panel data from waves 2005-2008, we find that, after controlling for time-invariant heterogeneities, those lost to follow-up in wave 2011 (i.e., attritors) did not differ significantly in objective measures of physical health and cognitive function from non-attritors, although the attritors were more likely to feel unhealthy during 2005-2008.

${ }^{20}$ According to Gu and Zeng (2004) and Gu (2008), the CLHLS generally has a lower loss-tofollow-up ratio than some panel surveys of older persons in the USA (e.g., Mihelic and Crimmins, 1997).
} 


\subsection{Nutrition Intake and Health Behavior}

One obvious mechanism is that pension income from the NRPS would relax the budget constraint and lead to changes in food consumption. Studies on the nutritional status of the Chinese elderly population show that the rural elderly suffered from insufficient intakes of protein and many micronutrients, as these levels were far below the recommended dietary allowances (Side et al., 1991; Shi et al., 2015). Poor nutrition is strongly associated with adverse health outcomes, such as frailty, morbidity, cognitive impairment, depression, and mortality (Cederholm et al., 1995; Ortega et al., 1997; Bartali et al., 2006; Woo et al., 2006).

The top part of Table 7 shows that pension status and income have significantly improved individuals' perceived financial sufficiency related to daily expenses. This improved sufficiency is further supported by the findings that the NRPS status and income have significantly increased the likelihood that the pensioners frequently consume protein-rich foods (meat, fish, and eggs). The income effect is small and insignificant for vitamin-rich foods (fruits and vegetables). This finding reflects the fact that protein-rich food is generally more expensive in rural areas, because most rural people eat vegetables they have grown themselves, but seldom purchase protein-rich food from the market.

\section{------Insert Table 7 here------}

Furthermore, we take a look at changes in smoking and drinking behaviors, as some evidence shows that tobacco is a normal good, especially among low-income people (Peck, 2011; Kenkel et al., 2014), and so is alcohol (Ruhm and Black, 2002). In the middle part of Table 7, it is worth noting that the pensioners have not spent the additional money on unhealthy consumption, such as smoking and drinking, suggesting no negative consequences of the increased pension income. Therefore, better nutrition intake with no increase in risky behaviors, resulting from the NRPS, could certainly contribute to improved health of the pensioners.

\subsection{Informal Care and Health Care Access}

Another obvious channel from income to health goes through informal care and health care access. As long-term care services are currently underdeveloped in China, 
informal care provided by spouses or children (especially sons) is still the most important source of care for the rural elderly (Giles et al., 2010; Li et al., 2013). An income increase may predict more health investments, via more family care or purchasing formal health care services (Sloan et al., 1997; Lei et al., 2015). Moreover, the literature shows that despite the development of a public health insurance system in rural China since 2003, financial difficulty is still the leading barrier faced by the rural elderly in access to health care (Cheng et al., 2015).

The bottom part of Table 7 examines the income effects of the NRPS on informal care received and health care accessibility of the pensioners. ${ }^{21}$ We can see that pension recipients have enjoyed more (although insignificantly so) hours of informal care from their children in the previous week. The pensioners are $6.3 \%$ more likely to have someone to talk with, and 3.4\% more likely to get help when having difficulties in daily life. Moreover, looking at the results for perceived access to health care, we find that the pensioners are also more likely to get adequate medical care when they are sick, and less likely to be unable to afford medical costs. When we look into the estimates of the income from the NRPS, we see similar findings.

\subsection{Labor Supply and Leisure}

Pension enrollment may have an impact on labor supply of the NRPS enrollees, and lead to a change in demand for leisure. Recent studies show that most elderly people in rural China work long hours, either in the formal sector (mainly farm work) or in the informal sector (household work), until they are no longer physically capable (Pang, et al., 2004; Giles et al., 2012). Increases in income or wealth can lead to a lower likelihood of doing physically demanding work (Benjamin et al., 2003; Giles et al., 2012), which would reduce the adverse effect of strenuous jobs on health outcomes (Fletcher et al., 2011; Giuntella and Mazzonna, 2015).

The upper part of Table 8 shows that the pensioners have significantly decreased their labor force participation rate by about 8 percentage points. Moreover, we examine

\footnotetext{
${ }^{21}$ We also find an insignificant income effect of the NRPS on the probability of receiving assistance from paid caregivers. However, less than 1 percent ( 24 observations) of the sample is receiving paid assistance. The results are not reported here but are available upon request.
} 
whether the pensioners spend more time doing household work or increase their leisure. Although OLS estimates are positive and significant, the FE-IV estimates indicate no significant increase in the likelihood of participating in household chores or grandchild care among the pensioners.

------Insert Table 8 here------

In contrast, the pensioners are $9.5 \%$ more likely to watch $\mathrm{TV}$ or listen to radio, and are $5.6 \%$ more likely to participate in social activities. Overall, their leisure index has increased by 0.21 units as a result of the NRPS enrollment. Similar patterns can be found when we turn to the roles of the income from the NRPS. Evidence in the literature shows that participation in social and leisure activities is beneficial to perceived physical health, cognitive function, and life satisfaction in old age (e.g., Payne et al., 2006; Verghese et al., 2003; Menec and Chipperfield, 1997).

\subsection{Perceived Relative Economic Status}

An indirect mechanism through which the NRPS appears to influence health is relative income. Some studies have argued that a low relative income may be associated with more psychosocial stress and worse health outcomes (Cohen et al., 1997; Wilkinson, 1997; Jones and Wildman, 2008).

Results in the bottom part of Table 8 show that pension recipients have significantly (at the 10\% level) improved their perceived economic status relative to the others in the local area. There is some evidence in the literature that perceived relative economic situation is significantly associated with disability, depression symptoms, and mortality risk among the elderly in Spain and Taiwan (e.g., Rodriguez-Laso et al., 2014; Collins and Goldman, 2008; Lee and Huang, 2015).

Moreover, although significant in the OLS estimation, the estimates in the FE-IV estimations show that the NRPS has no significant effect on the probability of pensioners involving themselves in household decision-making on financial spending. This finding is inconsistent with the corresponding studies on South Africa (Case and Menendez, 2007; Ambler, 2015). However, it is plausible given the family-binding eligibility criteria and low NRPS benefits at present. 


\subsection{Importance of Each Channel}

Table 9 assesses the relative importance of each channel in explaining the linkage between the NRPS and health outcomes. Column 1 shows the main results from column 3 of Table 3. Columns 2-6 add the five channel variables one at a time, and column 7 controls for all channel variables in the regression. The results show that increased access to health care and more leisure activities are important transmission channels for all health outcomes, especially for physical health outcome. Self-perceived relative economic status is another channel involving the positive effects of the NRPS on IADL. These channels explain $23 \%$ of the NRPS's impact on physical health.

------Insert Table 9 here-------

The main channels through which the NRPS improves cognitive function are improvements in informal care, ${ }^{22}$ leisure activities, nutritional intake, and health care access; they account for about $28 \%$ of the total effect of the NRPS enrollment on MMSE score. For the NRPS's impact on depression index, the two most important channels are access to health care and nutrition intake, followed by self-perceived relative economic status and leisure activities. The above channels can account for $38 \%$ of the overall effect of the NRPS on psychological well-being.

\section{Effects by Population Groups}

The results so far suggest that the NRPS has improved the health status of the pensioners through multiple channels. Another interesting issue deserving examination is whether the relationship between pension and health outcomes differs across some important dimensions, such as gender, age, living arrangement, and income.

These heterogeneous effects by gender and age are summarized in Table 10. Columns 1 and 2 present results for males and females separately. Pension enrollment has yielded similar health benefits for males and for females, except in IADL; only females have seen a significant improvement in IADL. The subgroup results for all

\footnotetext{
${ }^{22}$ Contrary to expectations, we find a negative association between the indicator of having someone to talk with in daily life and MMSE score in the middle part of Table 9, pointing to the possibility of reverse causality here.
} 
other health outcomes are similar to our main results based on the whole sample, suggesting that income has no differential effects by gender of the elderly on health. This is somewhat different from the previous literature; e.g., Jensen and Richter (2003) and Richter (2006) find that old men suffer more adverse health impact from pension loss or wage arrears than old women in Russia. One possible interpretation is that the males and females may respond to negative income shocks differently, but not to positive income shocks.

------Insert Table 10 here------

In columns 3 and 4, we divide the sample into two age groups, the eldest old (aged 85 and above) and younger old (aged 60-84). We can see that the NRPS is generally more effective on the younger-old group. Among this age group, pension recipients have significant better health outcomes, except self-reported general health, than nonrecipients. The eldest-old group has only seen significant improvements in cognitive function and height shrinkage. Further examination shows that compared with the younger-old group, the eldest-old group benefits more from the NRPS with respect to height shrinkage. One possible explanation is that height shrinkage, associated with poor nutritional status, is more pronounced in the eldest-old population than in the younger-old population (Huang et al., 2013), so the improved nutrition intake resulting from the NRPS may benefit them more in this regard.

During our study period, the level of pension benefits that the NRPS enrollees are entitled to is unrelated to their past work history, but is mainly determined by local governments; this pension income may have differential effects for different household types. As the benefits of the NRPS may be shared with other household members, we first examine the living arrangement dimension according to the baseline information. Columns 1 and 2 in Table 11 report results separately for respondents living in an extended household (i.e., with adult children or other adult members) and living independently (i.e., alone or with a spouse). Generally speaking, the results show that the NRPS has beneficial effects on physical health, cognitive function, and psychological well-being for the pensioners co-residing with other family members as well as for those living independently, but those living independently benefit more. This 
is consistent with Jensen and Richter (2003) and Case (2004), and suggests that the pensioners living alone are likely to retain more income from the NRPS for their own personal use and health.

------Insert Table 11 here------

To capture the differential generosity and relative importance of the NRPS benefits for different households, columns 3 and 4 of Table 11 divide the sample into two groups based on total household income in wave 2008/09. The higher income group (above mean income) have only seen decreases in height loss and self-reported depression index, whereas for the lower income group (below mean income) the NRPS has produced significant improvements in all health outcomes except, again, the selfreported health. This finding is not surprising, considering that the NRPS income matters more for the relatively poor elderly.

\section{Conclusion and Discussion}

This paper contributes to research on the casual effect of income on health outcomes. To deal with the two-way causal link between income and health, we estimate the effect of an income increase caused by the NRPS on multiple health measures of the elderly. Since its launch in 2009, the NRPS has been rolled out gradually to the whole country. This feature allows us to exploit the time variation of county-level program implementation as the instrumental variable, and employ a fixed effects approach with instrumental variable correction to address the endogeneity of enrollment into, or pension income from, the NRPS.

Our main results show that the NRPS status and income have had a beneficial effect on objective measures of physical health, cognitive function, and psychological well-being of the rural elderly. Consistent with the study of Johnston et al. (2009), we find no significant effect of pension status or income on self-reported general health. Our heterogeneous analyses by subpopulation groups have further suggested that the NRPS has generated more health benefits for the pensioners who are under age 85 , have lower household income, and live independently. 
Consistent with our main results based on the panel of the survivors, we also find that the pensioners were 6 percent (about $15.5 \%$ of the sample mean) less likely to die within the next three years following their receipt of basic pension benefit, which is equal to about 10 percent of pensioners' baseline household income. To understand the magnitude of this health effect better, we compare it with the estimates in the literature. In the two studies on the elderly aged 50 or older in Russia, Jensen and Richter (2003) find that a 24-percent decline in household income associated with pension arrears has increased the probability that male elderly die within the next two years by 6 percent (approximately $80 \%$ of the sample mean); and Richter (2006) finds that the mortality rate for male elderly between two survey rounds (one or two years) has been increased from $3.6 \%$ to $7.1 \%$ (nearly doubled) due to wage arrears that caused household income to drop by one-third. The implied income mortality elasticities in these two publications are two to four times ours in magnitude, probably because positive and negative income shocks may have different impacts on the well-being of the elderly. ${ }^{23}$

We investigate the mechanisms leading from the NRPS to health outcomes, and our results suggest that pension recipients respond to pension income in multiple ways. In particular, the pensioners not only get better access to health care, but also are more able to obtain informal care and have improved nutrition intake. The NRPS also allows the elderly to work less and have more leisure, which is beneficial for most health outcomes. Moreover, the improvement in self-perceived relative economic situation of elderly pensioners helps promote their physical function and mental well-being.

These findings have important policy implications for social protection in China and many other developing countries. In rural China, the basic social insurance system consists of the NRPS and a new rural cooperative medical system (NCMS). The NCMS is a heavily subsidized public health insurance program aiming to protect households from impoverishment due to catastrophic health expenditure. Cheng et al. (2015) show

\footnotetext{
${ }^{23}$ Another reason is that our study sample is much older and has a higher mortality rate than the sample of Russian elderly in Jensen and Richter (2003) and Richter (2006). As mortality in older populations is less sensitive to income, our implied income-mortality elasticity is much lower, though the marginal effects of the income shock are similar.
} 
that the NCMS enrollment has led to an improvement in physical and cognitive function of the elderly; however, most studies find little or only modest evidence that the NCMS or the basic public health insurance program in urban China have reduced out-of-pocket health expenditure (Wagstaff et al., 2009; Lei and Lin, 2009; Sun et al., 2009; Babiarz et al., 2012; Liu and Zhao, 2014; Cheng et al., 2015). The rising health care costs become an urgent challenge to the government. Our analysis provides another important rationale for developing social pensions in China, given the evidence that the NRPS has been able to improve health outcomes through both medical and non-medical mechanisms such as nutrition and leisure activities, while standard public health insurance programs have improved health mainly through provision of medical care. We believe that a fruitful area for future research would be to compare costs and benefits of these two types of social programs in the context of health economics. Moreover, our findings can also serve as a basis for formulating health-related interventions. For example, in some poor rural areas where it is difficult to deliver and maintain health interventions, direct cash transfers may be a cost-benefit intervention to improve health. 


\section{References}

Adams, Peter, Michael D. Hurd, Daniel McFadden, Angela Merrill, and Tiago Ribeiro. 2003. "Healthy, Wealthy, and Wise? Tests for Direct Causal Paths between Health and Socioeconomic Status." Journal of Econometrics 112: 3-56.

Ambler, Kate. 2015. "Bargaining with Grandma: The Impact of the South African Pension on Household Decision Making." Journal of Human Resources doi:10.3368/jhr.51.4.0314-6265R1.

Babiarz, Kimberly S., Grant Miller, Hongmei Yi, Linxiu Zhang, and Scott Rozelle. 2012. “China's New Cooperative Medical Scheme Improved Finances of Township Health Centers but Not the Number of Patients Served." Health Affairs 31(5): 1065-1074.

Barrientos, Armando. 2009. "Social Pensions in Low-Income Countries.” In Closing the Coverage Gap: The Role of Social Pensions and Other Retirement Income Transfers, ed. Robert Holzmann, David Robalino, and Noriyuki Takayama. Washington, DC: The World Bank.

Bartali, Benedetta, Edward A. Frongillo, Stefania Bandinelli, Fulvio Lauretani, Richard D. Semba, Linda P. Fried, and Luigi Ferrucci. 2006. "Low Nutrient Intake Is an Essential Component of Frailty in Older Persons." Journals of Gerontology. Series A: Biological Sciences and Medical Sciences 61(6): 589-593.

Becketti, Sean, Gould William, Lillard Lee, and Welch Finis. 1988. "The Panel Study of Income Dynamics after Fourteen Years: An Evaluation.” Journal of Labor Economics 6(4): 472-492.

Benjamin, Dwayne, Loren Brandt, and Jia-Zhueng Fan. 2003. "Ceaseless Toil? Health and Labor Supply of the Elderly in Rural China." William Davidson Institute Working Paper 579, Department of Economics, University of Toronto, Canada. 
Cai, Fang, John Giles, Philip O'Keefe, and Dewen Wang. 2012. “The Elderly and Old Age Support in Rural China: Challenges and Prospects.” Washington DC: World Bank.

Case, Anne. 2004. "Does Money Protect Health Status? Evidence from South African Pensions." In Perspectives on the Economics of Aging, ed. David Wise. University of Chicago Press: Chicago.

Case, Anne, and Alicia Menendez. 2007. "Does Money Empower the Elderly? Evidence from the Agincourt Demographic Surveillance Site, South Africa" Scandinavian Journal of Public Health 35(69): 157-164.

Cheng, Lingguo, Hong Liu, Ye Zhang, Ke Shen, and Yi Zeng. 2015. “The Impact of Health Insurance on Health Outcomes and Spending of The Elderly: Evidence From China's New Cooperative Medical Scheme.” Health Economics 24: 672691.

Cohen, Sheldon, Scott Line, Stephen B. Manuck, Bruce S. Rabin, Eugene R. Heise, and Jay R. Kaplan, 1997. “Chronic Social Stress, Social Status, and Susceptibility to Upper Respiratory Infections in Nonhuman Primates." Psychosomatic Medicine 59 (3), 213-221.

Collins, Amy Love, and Noreen Goldman, 2008. "Perceived Social Position and Health in Older Adults in Taiwan." Social Science \& Medicine 66(3): 536-544.

Crum, Rosa M., James C. Anthony, Susan S. Bassett, and Marshal F. Folstein. 1993. "Population-Based Norms for the Mini-Mental State Examination by Age and Educational Level." The Journal of the American Medical Association 269(18): 2386-2391.

Cutler, David M., Adriana Lleras-Muney, and Tom Vogl. 2008. "Socioeconomic Status and Health: Dimensions and Mechanisms.” NBER Working Paper No. 14333.

Deaton, Angus S., and Christina H. Paxson. 1998. "Aging and Inequality in Income and Health.” American Economic Review 88(2): 248-253.

Deaton, Angus. 2003. "Health, Inequality, and Economic Development." Journal of Economic Literature 41(1): 113-158. 
Ding, Weili, and Steven F. Lehrer. 2010. "Estimating Treatment Effects from Contaminated Multiperiod Education Experiments: The Dynamic Impacts of Class Size Reductions." The Review of Economics and Statistics 92(1): 31-42.

Ettner, Susan L. 1996. "New Evidence on the Relationship between Income and Health." Journal of Health Economics 15: 67-85.

Fletcher, Jason, M., L. Sindelar Jody, and Yamaguchi Shintaro. 2011. "Cumulative Effects of Job Characteristics on Health." Health Economics 20(5): 553-570.

Folstein, Marshal, F., Susan E. Folstein, and Paul R. McHugh. 1975. "Mini-Mental State: A Practical Method for Grading the Cognitive State of Patients for the Clinician.” Journal of Psychiatric Research 12(3): 189-198.

Frijters, Paul, John P. Haisken-DeNew, and Michael A. Shields. 2005. "The Causal Effect of Income on Health: Evidence from German Reunification.” Journal of Health Economics 24(5): 997-1017.

Gardner, Jonathan, and Andrew J. Oswald. 2004. "How is Mortality Affected by Money, Marriage and Stress?” Journal of Health Economics 23: 1181-1207.

Gardner, Jonathan, and Andrew J. Oswald. 2007. "Money and Mental Wellbeing: A Longitudinal Study of Medium-Sized Lottery Wins." Journal of Health Economics 26: 49-60.

Gerdtham, Ulf-G, and Magnus Johannesson. 2004. “Absolute Income, Relative Income, Income Inequality, and Mortality.” Journal of Human Resources 39(1): 228-247.

Giles, John, Dewen Wang, and Changbao Zhao. 2010. “Can China’s Rural Elderly Count on Support from Adult Children? Implications of Rural-to-Urban Migration.” Journal of Population Ageing 3(3):183-204.

Giles, John, Dewen Wang, and Wei Cai. 2012. "The Labor Supply and Retirement Behavior of China's Older Workers and Elderly in Comparative Perspective." In Aging in Asia: Findings from New and Emerging Data Initiatives, ed. James P. Smith and Malay Majmundar, National Academies Press: Washington DC.

Giuntella, Osea, and Fabrizio Mazzonna. 2015. "Do Immigrants Improve the Health of Natives?" Journal of Health Economics 43:140-153. 
Gu, Danan, and Yi Zeng. 2004. "Data Assessment of the Chinese Longitudinal Healthy Longevity Survey" (in Chinese). In Analysis on Determinants of Healthy Longevity in China, ed. Yi Zeng, Yuzhi Liu, Chunyuan Zhang, Zhenyu Xiao. Peking University Press: Beijing, China.

Gu, Danan. 2008. “General Data Quality Assessment of the CLHLS.” In Healthy Longevity in China, ed. Zeng Yi, Dudley L. Poston, Denese Ashbaugh Vlosky, and Danan Gu, 39-60. Dordrecht, the Neitherlands: Springer.

Heckman, James. 1990. "Varieties of Selection Bias." American Economic Review 80(2): 313-318.

Huang, Wei, Xiaoyan Lei, Geert Ridder, John Strauss, and Yaohui Zhao. 2013. "Health, Height, Height Shrinkage, and SES at Older Ages: Evidence from China." American Economic Journal: Applied Economics 5(2): 86-121.

Jensen, Robert T., and Kaspar Richter. 2003. "The Health Implications of Social Security Failure: Evidence from the Russian Pension Crisis.” Journal of Public Economics 88: 209-236.

Johnston, David W., Carol Propper, and Michael A. Shields. 2009. "Comparing Subjective and Objective Measures of Health: Evidence from Hypertension for the Income/Health Gradient.” Journal of Health Economics 28: 540-552.

Jones, Andrew M., and John Wildman. 2008. "Health, Income and Relative Deprivation: Evidence from the BHPS.” Journal of Health Economics 27: 308-324.

Jung, Juergen, and Chung Tran. 2012. "The Extension of Social Security Coverage in Developing Countries.” Journal of Development Economics 99: 439-458.

Kakwani, Nanak, and Kalanidhi Subbarao. 2005. "Aging and Poverty in Africa and the Role of Social Pensions." Social Protection Discussion Paper 521. Washington, DC: The World Bank.

Kenkel, Donald S., Maximilian D. Schmeiser, and Carly J, Urban. 2014. "Is Smoking Inferior? Evidence from Variation in the Earned Income Tax Credit." NBER Working Paper No. 20097. 
Kim, Jinyoung, and Emily Durden. 2007. "Socioeconomic Status and Age Trajectories of Health.” Social Science \& Medicine 65:2489-2502.

Lee, Miaw-Chwen, and Nicole Huang. 2015. "Changes in Self-Perceived Economic Satisfaction and Mortality at Old Ages: Evidence from a Survey of Middle-Aged and Elderly Adults in Taiwan." Social Science \& Medicine 130:1-8.

Lei, Xiaoyan, and Wanchuan Lin. 2009. "The New Cooperative Medical Scheme in Rural China: Does More Coverage Mean More Service and Better Health?” Health Economics 18(S2): S25-S46.

Lei, Xiaoyan, John Strauss, Meng Tian, and Yaohui Zhao. 2015. "Living Arrangements of the Elderly in China: Evidence from the CHARLS National Baseline." China Economic Journal 8(3): 191-214.

Li, Mei, Yang Zhang, Zhenyu Zhang, Ying Zhang, Litao Zhou, and Kun Chen. 2013. "Rural-Urban Differences in the Long-Term Care of the Disabled Elderly in China." PLoS One 8(11): e79955.

Lindahl, Mikael. 2005. "Estimating the Effect of Income on Health and Mortality Using Lottery Prizes as an Exogenous Source of Variation in Income." The Journal of Human Resources 40(1): 144-168.

Liu, Hong, and Zhong Zhao. 2014. "Does Health Insurance Matter? Evidence from China's Urban Resident Basic Medical Insurance." Journal of Comparative Economics 42: 1007-1020.

Meer, Jonathan, Douglas L. Miller, and Harvey S. Rosen. 2003. "Exploring the HealthWealth Nexus.” Journal of Health Economics 22: 713-730.

Menec, Verena H., and Judith G. Chipperfield. 1997. "The Role of Locus of Control in Seniors' Leisure Activity Participation, Health, and Life Satisfaction.” Journal of Aging Health 9(1): 105-125.

Michaud, Pierre-Carl, and Arthur van Soest. 2008. "Health and Wealth of Elderly Couples: Causality Tests Using Dynamic Panel Data Models.” Journal of Health Economics 27(5): 1312-1325. 
Mihelic, Adrienne H., and Eileen M. Crimmins. 1997. "Loss to Follow-Up in a Sample of Americans 70 Years of Age and Older: The LSOA 1984-1990.” The Journals of Gerontology Series B: Psychological Sciences and Social Sciences 52B(1): S37-S48.

Ortega, Rosa M., Ana M. Requejo, Pedro Andrés, Ana M. López-Sobaler, M. Elena Quintas, M. Rosario Redondo, Beatriz Navia, and Trinidad Rivas. 1997. "Dietary Intake and Cognitive Function in a Group of Elderly People.” The American Journal of Clinical Nutrition 66(4): 803-809.

Palacios, Robert, and Oleksiy Sluchynsky. 2006. "Social Pensions Part I: Their Role in the Overall Pension System." Social Protection Discussion Paper 36237. World Bank, Washington, DC.

Pang, Lihua, Alan de Brauw, and Scott Rozelle. 2004. "Working until You Drop: The Elderly of Rural China.” China Journal 52: 73-96.

Payne, Laura L., Andrew J. Mowen, and Julian Montoro-Rodriguez. 2006. "The Role of Leisure Style in Maintaining the Health of Older Adults with Arthritis". Journal of Leisure Research 38(1): 20-45.

Peck, Richard M. 2011. "Equity Issues, Tobacco, and the Poor." In World Bank Economics of Tobacco Toolkit, ed. Ayda Yurekli and Joy de Beyer. Washington, DC: The World Bank.

Propper, Carol, Kelvyn Jones, Anne Bolster, Simon Burgess, Ron Johnstond, and Rebecca Sarker. 2005. "Local Neighbourhood and Mental Health: Evidence from the UK." Social Science and Medicine 61(10): 2065-2083.

Richter, Kaspar. 2006. "The Well-Being of the Elderly and Wage Arrears in Russia," Journal of the European Economic Association 4(1): 116-152.

Rodriguez-Laso, Angel, Antonio Abellan, Mayte Sancho, Rogelio Pujol, Ignacio Montorio, and Purificación Diaz-Veiga. 2014. "Perceived Economic Situation, but Not Education Level, Is Associated with Disability Prevalence in the Spanish Elderly: Observational Study.” BMC Geriatrics 14: 60. 
Ruhm, Christopher J., and William E. Black. 2002, “Does Drinking Really Decrease in Bad Times?" Journal of Health Economics 21(4): 659-678.

Shi, Shih-Jiunn. 2006. "Left to Market and Family - Again? Ideas and the Development of the Rural Pension Policy in China." Social Policy and Administration 40(7): 791-806.

Shi, R., J. Duan, Y. Deng, Q. Tu, Y. Cao, M. Zhang, Q. Zhu, and Y. Lü. 2015. "Nutritional Status of an Elderly Population in Southwest China: A CrossSectional Study Based on Comprehensive Geriatric Assessment.” The Journal of Nutrition, Health \& Aging 19(1): 26-32.

Side, X, S. Mingtang, Z. Shuquan, M. Zhaomei, X. Yinzhi, L. Yujun, W. Jun, and J. Kui. 1991. "Anthropometric and Dietary Survey of Elderly Chinese." The British Journal of Nutrition 66(3):355-362.

Sloan, Frank, Gabriel Picone, and Thomas J. Hoerger. 1997. "The Supply of Children's Time to Disabled Elderly Parents," Economic Inquiry 35(2): 295-308.

Smith, James P. 2007. "The Impact of Socioeconomic Status on Health over the LifeCourse.” Journal of Human Resources 42(4): 739-764.

Smith, James. 1998. "Socioeconomic Status and Health." American Economic Review Papers and Proceedings 88: 192-196.

Smith, James P. 1999. "Healthy Bodies and Thick Wallets: The Dual Relationship between Health and Economic Status.” Journal of Economic Perspectives 13(2): $145-166$.

Smith, Kimberly V., and Noreen Goldman. 2007. "Socioeconomic Differences in Health among Older Adults in Mexico." Social Science Medicine. 65(7): 13721385 .

Sun, Xiaoyun, Sukhan Jackson, Gordon Carmichael, and Adrian C. Sleigh. 2009. "Catastrophic Medical Payment and Financial Protection in Rural China: Evidence from the New Cooperative Medical Scheme in Shandong Province.” Health Economics 18(1): 103-119. 
Snyder, Stephen E., and William N. Evans. 2006. "The Impact of Income on Mortality: Evidence from the Social Security Notch.” Review of Economics and Statistics 88(3): 482-495.

van Doorslaer, Eddy, Adam Wagstaff, Han Bleichrodt, Samuel Calonge, Ulf-G. Gerdtham, Michael Gerfin, José Geurts, Lorna Gross, Unto Häkkinen, Robert E. Leu, Owen O'Donell, Carol Propper, Frank Puffer, Marisol Rodríguez, Gun Sundberg, and Olaf Winkelhake. 1997. "Income-Related Inequalities in Health: Some International Comparisons.” Journal of Health Economics 16: 93-112.

Verghese, Joe, Richard B. Lipton, Mindy J. Katz, Charles B. Hall, Carol A. Derby, Gail Kuslansky, Anne F. Ambrose, Martin Sliwinski, and Herman Buschke. 2003. "Leisure Activities and the Risk of Dementia in the Elderly." New England Journal of Medicine 348(25): 2508-2516.

Wagstaff, Adam, Lindelow Magnus, Jun Gao, Ling Xu, and Juncheng Qian. 2009. "Extending Health Insurance to the Rural Population: An Impact Evaluation of China's New Cooperative Medical Scheme.” Journal of Health Economics 28(1): $1-19$.

Wang, Dewen. 2006. “China's Urban and Rural Old Age Security System: Challenges and Options." China \& World Economy 14(1): 102-116.

Wilkinson, Richard G., and Kate E. Pickett. 2006. "Income Inequality and Population Health: A Review and Explanation of the Evidence." Social Science \& Medicine 62(7): 1768-1784.

Wilkinson, Richard G., 1997. "Health Inequalities: Relative or Absolute Material Standards?" British Medical Journal 314: 591-595.

Woo, J., H. Lynn, W. Y. Lau, J. Leung, E. Lau, S. Y. S. Wong, and T. Kwok. 2006. "Nutrient Intake and Psychological Health in an Elderly Chinese Population". International Journal of Geriatric Psychiatry 21(11): 1036-1043.

Zeng, Yi, James W. Vaupe, Zhenyu Xiao, Chunyuan Zhang, and Yuzhi Liu. 2002. "Sociodemographic and Health Profiles of the Oldest-old in China." Population and Development Review 28: 251-273. 
Zimmer, Zachary, and Pattama Amornsirisomboon. 2001. "Socioeconomic Status and Health among Older Adults in Thailand: An Examination Using Multiple Indicators." Social Science and Medicine 52(8): 1297-1311. 


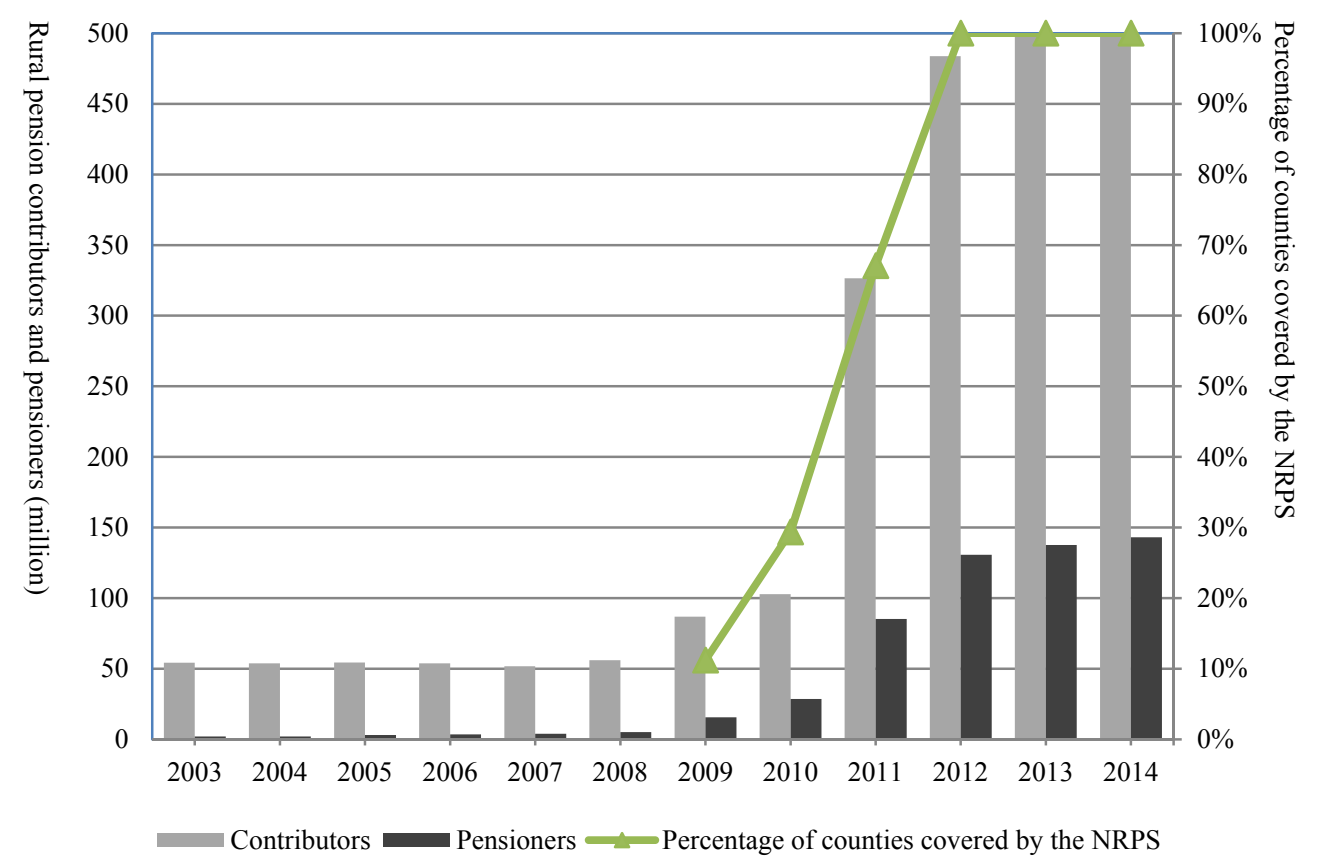

Figure 1 the Coverage of the Rural Pension System (2003-2014)

Notes:

(a) Data source: China's Ministry of Human Resources and Social Security (MHRSS), Statistic Bulletin on Human Resources and Social Security Development 2002-2014.

(b) Rural pension system refers to the local pilots of rural pension prior to 2009 and the NRPS from 2009 and after. 
Table 1 Descriptive Statistics of Health and Economic Status

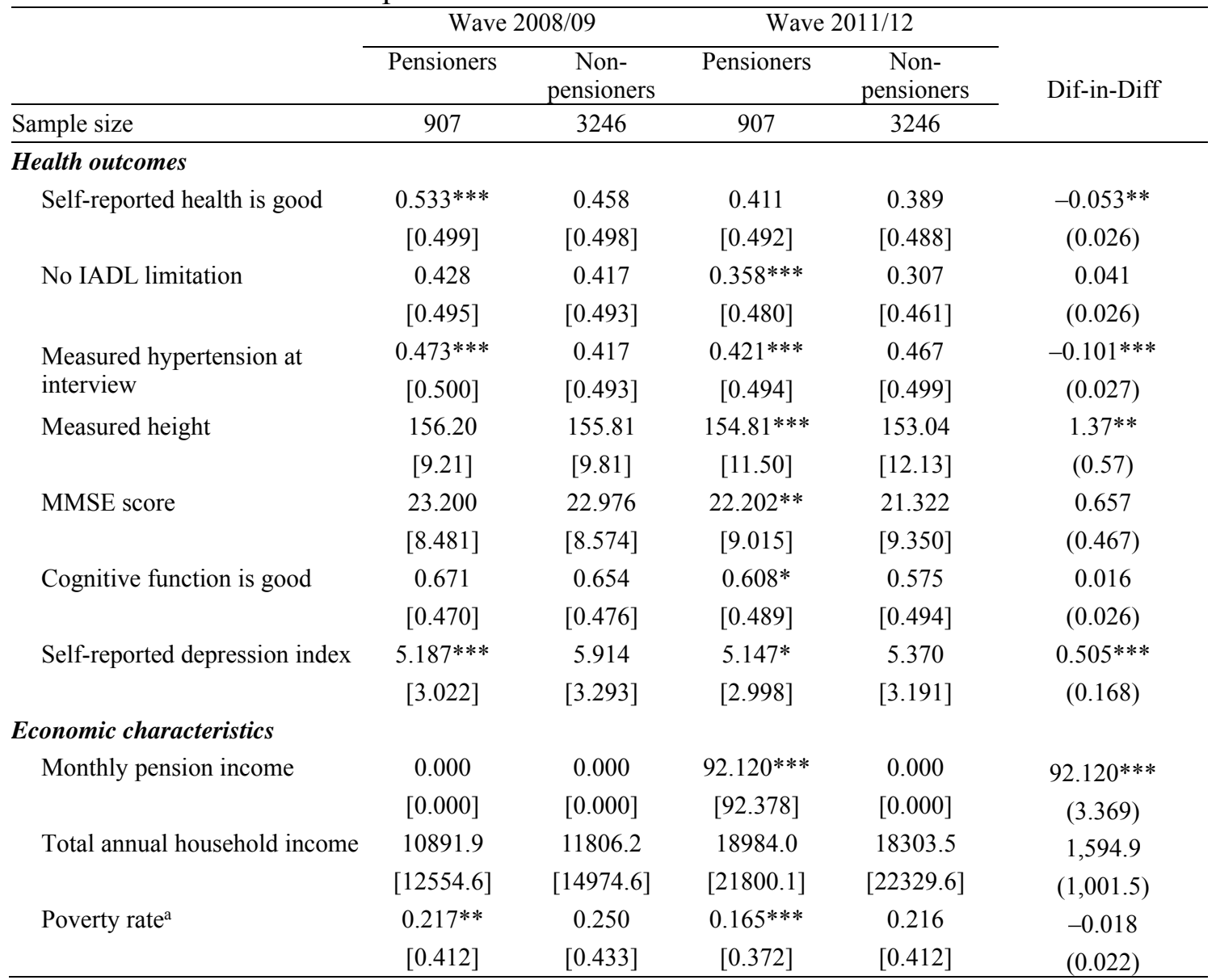

Notes:

(a) Standard deviation in square brackets; robust standard errors in parenthesis.

(b) $t$-test was applied for pairwise comparisons of the treated and control groups in each wave. ${ }^{*} p<0.10,{ }^{* *} p<0.05$, $* * * p<0.01$.

(c) We use the 2009 official rural poverty line of 1,196 Chinese yuan (\$176). 
Table 2 Descriptive Statistics of Individual and Household Characteristics

\begin{tabular}{|c|c|c|c|c|c|}
\hline \multirow{2}{*}{ Variable } & \multirow{2}{*}{ Full Sample } & \multicolumn{2}{|c|}{ Wave 2008} & \multicolumn{2}{|c|}{ Wave 2011} \\
\hline & & Pensioners & Non-pensioners & Pensioners & Non-pensioners \\
\hline Sample size & 8306 & 907 & 3246 & 907 & 3246 \\
\hline \multicolumn{6}{|c|}{ Potential channels from income to health } \\
\hline \multirow{2}{*}{$\begin{array}{l}\text { Have sufficient financial } \\
\text { support for daily expenses }\end{array}$} & 0.736 & $0.762 * * *$ & 0.718 & $0.781 * * *$ & 0.735 \\
\hline & {$[0.441]$} & {$[0.426]$} & {$[0.450]$} & {$[0.414]$} & {$[0.442]$} \\
\hline \multirow{2}{*}{$\begin{array}{l}\text { Frequent intake of protein-rich } \\
\text { food }\end{array}$} & 0.531 & 0.535 & 0.515 & 0.540 & 0.543 \\
\hline & [0.499] & {$[0.499]$} & {$[0.500]$} & {$[0.499]$} & {$[0.498]$} \\
\hline \multirow{2}{*}{$\begin{array}{l}\text { Frequent intake of vitamin-rich } \\
\text { food }\end{array}$} & 0.591 & $0.701 * * *$ & 0.622 & $0.590 * * *$ & 0.530 \\
\hline & {$[0.492]$} & {$[0.458]$} & {$[0.485]$} & {$[0.492]$} & [0.499] \\
\hline \multirow[t]{2}{*}{ Smoking } & 0.190 & 0.212 & 0.198 & 0.195 & 0.175 \\
\hline & {$[0.393]$} & {$[0.409]$} & [0.399] & {$[0.396]$} & {$[0.380]$} \\
\hline \multirow[t]{2}{*}{ Drinking } & 0.183 & $0.245 * * *$ & 0.184 & $0.197 * *$ & 0.161 \\
\hline & {$[0.387]$} & {$[0.430]$} & [0.388] & {$[0.398]$} & {$[0.368]$} \\
\hline \multirow{2}{*}{$\begin{array}{l}\text { Hours of care received from } \\
\text { children last week }\end{array}$} & 7.293 & 2.810 & 4.015 & 10.101 & 11.134 \\
\hline & {$[26.948]$} & [14.929] & [20.641] & {$[29.810]$} & [33.129] \\
\hline \multirow{2}{*}{$\begin{array}{l}\text { Have someone to talk with in } \\
\text { daily life }\end{array}$} & 0.946 & 0.953 & 0.945 & $0.964 * * *$ & 0.941 \\
\hline & {$[0.225]$} & {$[0.213]$} & {$[0.228]$} & {$[0.186]$} & {$[0.235]$} \\
\hline \multirow{2}{*}{$\begin{array}{l}\text { Get help when having } \\
\text { problems/difficulties }\end{array}$} & 0.976 & 0.972 & 0.978 & $0.984^{*}$ & 0.973 \\
\hline & {$[0.153]$} & {$[0.164]$} & {$[0.148]$} & {$[0.125]$} & {$[0.163]$} \\
\hline \multirow{2}{*}{$\begin{array}{l}\text { Get sufficient medical care } \\
\text { when sick }\end{array}$} & 0.913 & 0.921 & 0.904 & $0.939 * *$ & 0.914 \\
\hline & {$[0.281]$} & [0.271] & {$[0.294]$} & {$[0.239]$} & {$[0.281]$} \\
\hline \multirow{2}{*}{$\begin{array}{l}\text { Fail to get necessary care due } \\
\text { to costs }\end{array}$} & 0.044 & $0.042 *$ & 0.058 & 0.026 & 0.035 \\
\hline & {$[0.205]$} & {$[0.201]$} & {$[0.234]$} & {$[0.158]$} & {$[0.185]$} \\
\hline \multirow[t]{2}{*}{ Still work } & 0.162 & $0.197 * *$ & 0.166 & $0.176^{* *}$ & 0.144 \\
\hline & {$[0.368]$} & {$[0.398]$} & {$[0.372]$} & {$[0.381]$} & {$[0.351]$} \\
\hline \multirow{2}{*}{$\begin{array}{l}\text { Do household chores or } \\
\text { grandchild care everyday }\end{array}$} & 0.497 & 0.547 & 0.546 & 0.467 & 0.442 \\
\hline & {$[0.500]$} & {$[0.498]$} & {$[0.498]$} & {$[0.499]$} & {$[0.497]$} \\
\hline \multirow[t]{2}{*}{ Leisure index } & 0.661 & 0.677 & 0.659 & $0.740 * * *$ & 0.636 \\
\hline & {$[0.771]$} & {$[0.736]$} & {$[0.749]$} & {$[0.807]$} & {$[0.790]$} \\
\hline \multirow{2}{*}{$\begin{array}{l}\text { Perceived relative economic } \\
\text { status is high }\end{array}$} & 0.122 & 0.108 & 0.103 & $0.162 * *$ & 0.133 \\
\hline & {$[0.340]$} & {$[0.311]$} & {$[0.305]$} & {$[0.465]$} & {$[0.340]$} \\
\hline Can make decisions on & 0.332 & 0.353 & 0.333 & $0.371 * * *$ & 0.314 \\
\hline household spending & {$[0.471]$} & {$[0.478]$} & {$[0.471]$} & {$[0.483]$} & {$[0.464]$} \\
\hline Control variables & & & & & \\
\hline Age & 84.54 & 82.46 & 83.15 & 85.56 & 86.23 \\
\hline & {$[11.26]$} & {$[10.93]$} & {$[11.23]$} & {$[10.90]$} & {$[11.21]$} \\
\hline Male & 0.411 & 0.430 & 0.406 & 0.430 & 0.406 \\
\hline & {$[0.492]$} & {$[0.495]$} & {$[0.491]$} & {$[0.495]$} & {$[0.491]$} \\
\hline Had a white-collar career & 0.012 & 0.015 & 0.011 & 0.015 & 0.011 \\
\hline before age 60 & {$[0.107]$} & {$[0.123]$} & {$[0.102]$} & {$[0.123]$} & {$[0.102]$} \\
\hline Han & 0.920 & $0.957 * * *$ & 0.909 & $0.957 * * *$ & 0.909 \\
\hline & {$[0.272]$} & {$[0.203]$} & {$[0.288]$} & {$[0.203]$} & {$[0.288]$} \\
\hline Married & 0.356 & 0.399 & 0.374 & $0.371 * * *$ & 0.322 \\
\hline & {$[0.479]$} & {$[0.490]$} & {$[0.484]$} & {$[0.483]$} & {$[0.467]$} \\
\hline Years of schooling & 1.507 & 1.615 & 1.477 & 1.615 & 1.477 \\
\hline & [2.584] & {$[2.596]$} & [2.581] & {$[2.596]$} & [2.581] \\
\hline Household size & 3.304 & 3.159 & 3.209 & 3.370 & 3.424 \\
\hline & {$[2.045]$} & [1.849] & {$[1.977]$} & [2.131] & [2.132] \\
\hline Owns the home & 0.429 & 0.482 & 0.471 & 0.403 & 0.380 \\
\hline & {$[0.495]$} & {$[0.500]$} & [0.499] & {$[0.491]$} & {$[0.485]$} \\
\hline Number of living children & 4.003 & $4.138 * *$ & 3.980 & $4.096^{* *}$ & 3.961 \\
\hline & {$[1.796]$} & {$[1.806]$} & [1.791] & {$[1.820]$} & {$[1.791]$} \\
\hline Have health insurance & 0.824 & $0.808 * * *$ & 0.756 & $0.933 * * *$ & 0.865 \\
\hline & {$[0.381]$} & {$[0.394]$} & {$[0.430]$} & {$[0.250]$} & {$[0.342]$} \\
\hline
\end{tabular}

Notes: Standard deviation in square brackets. $t$-test was applied for pairwise comparisons of the two groups in each wave. ${ }^{*} p<0.10, * * p<0.05, * * * p<0.01$. 
Table 3 Effects of Pension Income on Health Outcomes

\begin{tabular}{|c|c|c|c|c|c|c|}
\hline & \multicolumn{3}{|c|}{ Coefficient on NRPS take-up } & \multicolumn{3}{|c|}{ Coefficient on $\ln (N R P S$ income) } \\
\hline & OLS & FE & FE-IV & OLS & FE & FE-IV \\
\hline & $(1)$ & $(2)$ & (3) & $(4)$ & (5) & $(6)$ \\
\hline Self-reported health is & -0.007 & $-0.047 *$ & -0.034 & -0.001 & -0.009 & -0.009 \\
\hline good & $(0.019)$ & $(0.025)$ & $(0.057)$ & $(0.005)$ & $(0.006)$ & $(0.013)$ \\
\hline Observations & 8,007 & 7,926 & 7,926 & 7,859 & 7,630 & 7,630 \\
\hline No IADL limitation & $0.040 * * *$ & $0.045^{* *}$ & $0.113 * *$ & $0.011 * * *$ & $0.012 * *$ & $0.024 * *$ \\
\hline & $(0.015)$ & $(0.019)$ & $(0.046)$ & $(0.004)$ & $(0.005)$ & $(0.011)$ \\
\hline Observations & 8,014 & 7,940 & 7,940 & 7,866 & 7,644 & 7,644 \\
\hline Measured & $-0.067 * * *$ & $-0.091 * * *$ & $-0.211 * * *$ & $-0.016^{* * *}$ & $-0.021 * * *$ & $-0.054 * * *$ \\
\hline hypertension at & & & & & & \\
\hline interview & $(0.020)$ & $(0.027)$ & $(0.062)$ & $(0.005)$ & $(0.007)$ & $(0.015)$ \\
\hline Observations & 7,799 & 7,530 & 7,530 & 7,653 & 7,252 & 7,252 \\
\hline Measured height & $1.043 * * *$ & $1.628 * * *$ & $3.491 * * *$ & $0.192 * *$ & $0.331 * * *$ & $0.798 * * *$ \\
\hline & $(0.351)$ & $(0.381)$ & $(0.846)$ & $(0.088)$ & $(0.094)$ & $(0.198)$ \\
\hline Observations & 7,698 & 7,346 & 7,346 & 7,565 & 7,082 & 7,082 \\
\hline MMSE score & $0.682 * *$ & 0.518 & $2.251 * * *$ & $0.164 * *$ & $0.159 *$ & $0.572 * * *$ \\
\hline & $(0.305)$ & $(0.338)$ & $(0.779)$ & $(0.075)$ & $(0.082)$ & $(0.182)$ \\
\hline Observations & 8,009 & 7,930 & 7,930 & 7,861 & 7,634 & 7,634 \\
\hline Cognitive function is & 0.023 & 0.011 & $0.178 * * *$ & 0.006 & 0.005 & $0.042 * * *$ \\
\hline good & $(0.017)$ & $(0.020)$ & $(0.047)$ & $(0.004)$ & $(0.005)$ & $(0.011)$ \\
\hline Observations & 8,009 & 7,930 & 7,930 & 7,861 & 7,634 & 7,634 \\
\hline Self-reported & 0.031 & $0.484 * * *$ & $-1.461 * * *$ & 0.006 & $0.116^{* * *}$ & $-0.301 * * *$ \\
\hline depression index & $(0.124)$ & $(0.164)$ & $(0.419)$ & $(0.031)$ & $(0.040)$ & (0.099) \\
\hline Observations & 7,468 & 6,992 & 6,992 & 7,333 & 6,740 & 6,740 \\
\hline \multicolumn{7}{|c|}{ First-stage coefficients on IV } \\
\hline Program duration in the & - & - & $0.021 * * *$ & - & - & $0.089 * * *$ \\
\hline county (months) & - & - & $(0.001)$ & - & - & $(0.003)$ \\
\hline Observations & & & 7,940 & & & 7,644 \\
\hline
\end{tabular}

(a) Robust standard errors are reported in parenthesis; ${ }^{*} p<0.10$, ${ }^{* *} p<0.05, * * * p<0.01$.

(b) All regressions include age, age squared/100, married, number of living children, household size, health insurance coverage, homeownership, and wave dummies. OLS estimations also include controls for gender, married status, ethnicity, years of schooling, a dummy variable for having a white-collar career before age 60 , and province dummies. 
Table 4 Tests of the Validity of the Identification Assumption

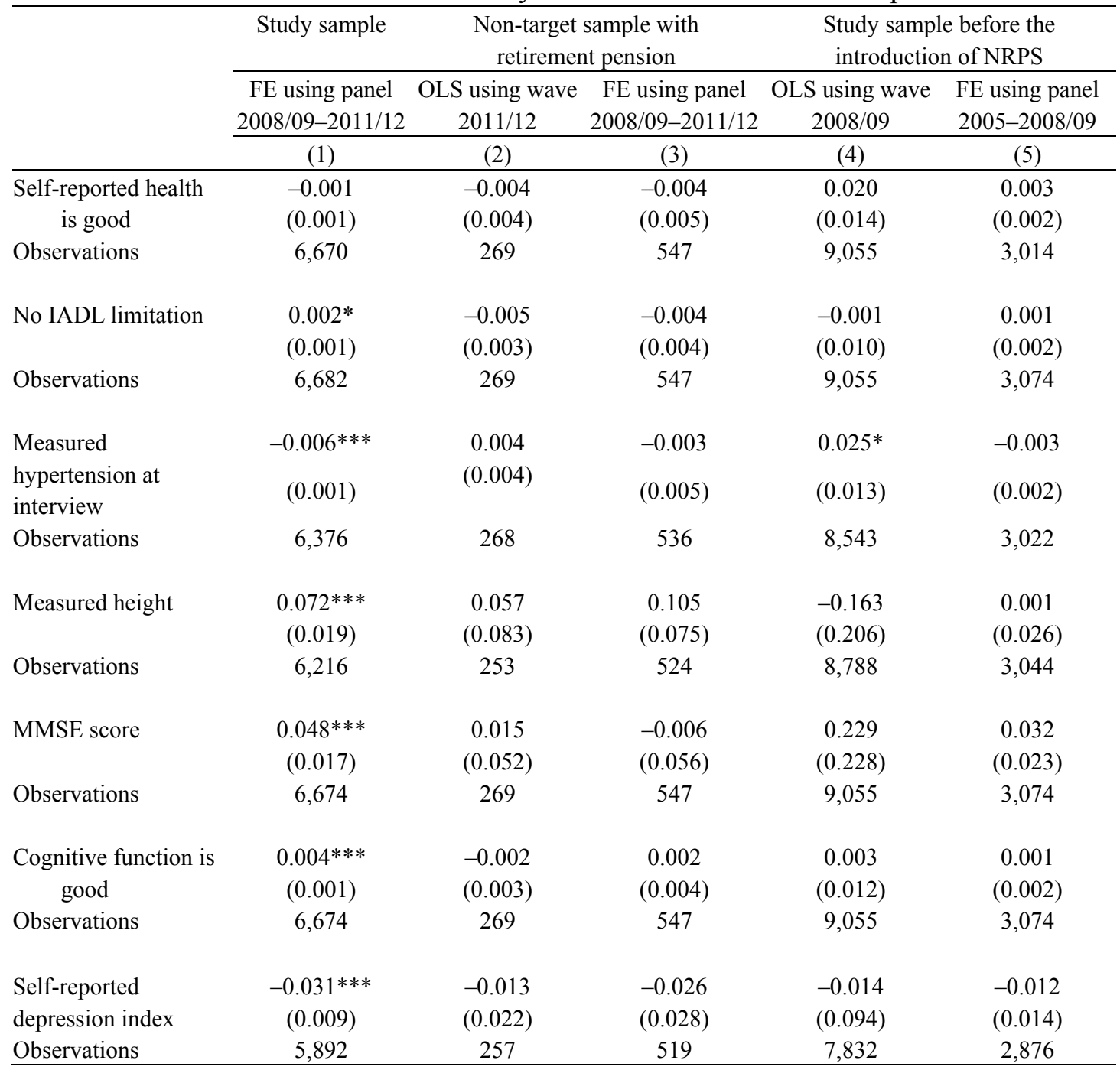

Notes:

(a) Robust standard errors are reported in parenthesis; * $p<0.10, * * p<0.05, * * * p<0.01$.

(b) In each cell of columns (1)-(3) and (5), we report the estimates for program duration of the NRPS in the county (months). In each cell of column (4), we report the estimates for the indicator variable for 2009-2010 pilot counties.

(c) All regressions include age, age squared/100, married, number of living children, household size, health insurance coverage, homeownership, and wave dummies. OLS estimations also include controls for gender, married status, ethnicity, years of schooling, a dummy variable for having a white-collar career before age 60, and province dummies. 
Table 5 Effects of Pension Income on Mortality

\begin{tabular}{|c|c|c|c|c|}
\hline & \multicolumn{4}{|c|}{$\begin{array}{c}\text { Dependent variable is whether individual died between 2011/12 and } 2014 \\
\text { surveys }\end{array}$} \\
\hline & Probit & IV Probit & Probit & IV Probit \\
\hline & $(1)$ & (2) & (3) & (4) \\
\hline \multirow[t]{2}{*}{ NRPS enrollment } & 0.021 & $-0.061 *$ & & \\
\hline & $(0.016)$ & $(0.037)$ & & \\
\hline \multirow[t]{2}{*}{$\ln ($ pension income $)$} & & & 0.005 & $-0.014 *$ \\
\hline & & & $(0.004)$ & $(0.008)$ \\
\hline \multirow[t]{2}{*}{ Age } & $0.037 * * *$ & $0.038 * * *$ & $0.038 * * *$ & $0.039 * * *$ \\
\hline & $(0.010)$ & $(0.010)$ & $(0.010)$ & $(0.010)$ \\
\hline \multirow[t]{2}{*}{ Age squared/100 } & $-0.015^{* * *}$ & $-0.016 * * *$ & $-0.015 * * *$ & $-0.016 * * *$ \\
\hline & $(0.006)$ & $(0.006)$ & $(0.006)$ & $(0.006)$ \\
\hline \multirow[t]{2}{*}{ Married } & $-0.056^{* * *}$ & $-0.054 * * *$ & $-0.060 * * *$ & $-0.058 * * *$ \\
\hline & $(0.017)$ & $(0.016)$ & $(0.017)$ & $(0.017)$ \\
\hline \multirow[t]{2}{*}{ Number of adult children } & -0.003 & -0.003 & -0.002 & -0.002 \\
\hline & $(0.003)$ & $(0.003)$ & $(0.003)$ & $(0.003)$ \\
\hline \multirow[t]{2}{*}{ Household size } & $0.006^{*}$ & $0.006^{* *}$ & $0.006^{* *}$ & $0.007 * *$ \\
\hline & $(0.003)$ & $(0.003)$ & $(0.003)$ & $(0.003)$ \\
\hline \multirow[t]{2}{*}{ Owns the home } & 0.000 & 0.000 & 0.005 & 0.006 \\
\hline & $(0.015)$ & $(0.015)$ & $(0.015)$ & $(0.015)$ \\
\hline \multirow[t]{2}{*}{ Have health insurance } & $-0.047 * *$ & $-0.041 * *$ & $-0.049 * *$ & $-0.042 * *$ \\
\hline & $(0.020)$ & $(0.019)$ & $(0.020)$ & $(0.019)$ \\
\hline \multirow[t]{2}{*}{ No IADL impairment } & $-0.142 * * *$ & $-0.139 * * *$ & $-0.143 * * *$ & $-0.139 * * *$ \\
\hline & $(0.017)$ & $(0.017)$ & $(0.018)$ & $(0.017)$ \\
\hline \multirow[t]{2}{*}{ MMSE score } & $-0.009 * * *$ & $-0.009 * * *$ & $-0.009 * * *$ & $-0.009 * * *$ \\
\hline & $(0.001)$ & $(0.001)$ & $(0.001)$ & $(0.001)$ \\
\hline \multirow[t]{2}{*}{ Male } & $0.121 * * *$ & $0.120 * * *$ & $0.121 * * *$ & $0.119 * * *$ \\
\hline & $(0.015)$ & $(0.015)$ & $(0.015)$ & $(0.015)$ \\
\hline \multirow[t]{2}{*}{ Han } & -0.032 & -0.025 & -0.033 & -0.026 \\
\hline & $(0.026)$ & $(0.026)$ & $(0.026)$ & $(0.026)$ \\
\hline \multirow{2}{*}{$\begin{array}{l}\text { Had a white-collar job } \\
\text { before age } 60\end{array}$} & 0.048 & 0.050 & 0.031 & 0.033 \\
\hline & $(0.063)$ & $(0.060)$ & $(0.065)$ & $(0.062)$ \\
\hline \multirow[t]{2}{*}{ Years of schooling } & $0.006^{* *}$ & $0.007 * *$ & $0.007 * *$ & $0.007 * *$ \\
\hline & $(0.003)$ & $(0.003)$ & $(0.003)$ & $(0.003)$ \\
\hline Province dummy & Yes & Yes & Yes & Yes \\
\hline Observations & 4,322 & 4,573 & 4,180 & 4,424 \\
\hline
\end{tabular}

\section{Notes:}

(a) Marginal effects are reported with robust standard errors in parenthesis; $* p<0.10, * * p<0.05, * * * p<0.01$.

(b) We use data from wave 2011/12 and restrict the sample to the rural elderly without any non-NRPS pension. 
Table 6 Intent-to-treat effect of the NRPS on Mortality

\begin{tabular}{|c|c|c|}
\hline & Treated: target sample & Control: retired pensioners \\
\hline \multicolumn{3}{|l|}{ A. 3-year mortality rate } \\
\hline \multirow[t]{2}{*}{ Respondents in wave 2005} & 0.426 & 0.189 \\
\hline & {$[N=6,209]$} & {$[N=254]$} \\
\hline \multirow[t]{2}{*}{ Respondents in wave $2008 / 09$} & 0.443 & 0.253 \\
\hline & {$[N=7,742]$} & {$[N=372]$} \\
\hline \multirow[t]{2}{*}{ Respondents in wave 2011/12 } & 0.339 & 0.198 \\
\hline & {$[N=4,870]$} & {$[N=353]$} \\
\hline \multicolumn{3}{|l|}{ B. DID estimation results } \\
\hline \multirow[t]{2}{*}{ Wave $2008 / 09 *$ treatment status } & -0.047 & -0.028 \\
\hline & $(0.034)$ & $(0.032)$ \\
\hline \multirow[t]{2}{*}{ Wave $2011 / 12 *$ treatment status } & $-0.096 * * *$ & $-0.055^{*}$ \\
\hline & $(\mathbf{0 . 0 3 4 )}$ & $(0.032)$ \\
\hline \multirow[t]{2}{*}{ Wave $2008 / 09$} & $0.064 *$ & 0.019 \\
\hline & $(0.033)$ & $(0.031)$ \\
\hline \multirow[t]{2}{*}{ Wave $2011 / 12$} & 0.009 & -0.015 \\
\hline & $(0.033)$ & $(0.031)$ \\
\hline \multirow[t]{2}{*}{ Treatment status } & $0.237 * * *$ & $0.111 * * *$ \\
\hline & $(0.025)$ & $(0.025)$ \\
\hline \multirow[t]{2}{*}{ Age } & & 0.000 \\
\hline & & $(0.004)$ \\
\hline \multirow[t]{2}{*}{ Age squared/100 } & & $0.008 * * *$ \\
\hline & & $(0.002)$ \\
\hline \multirow[t]{2}{*}{ Married } & & $-0.030 * * *$ \\
\hline & & $(0.008)$ \\
\hline \multirow[t]{2}{*}{ Number of adult children } & & $-0.003^{*}$ \\
\hline & & $(0.002)$ \\
\hline \multirow[t]{2}{*}{ Household size } & & $0.004^{* *}$ \\
\hline & & $(0.002)$ \\
\hline \multirow[t]{2}{*}{ Owns the home } & & -0.011 \\
\hline & & $(0.007)$ \\
\hline \multirow[t]{2}{*}{ Have health insurance } & & -0.002 \\
\hline & & $(0.009)$ \\
\hline \multirow[t]{2}{*}{ No IADL impairment } & & $-0.108 * * *$ \\
\hline & & $(0.008)$ \\
\hline \multirow[t]{2}{*}{ MMSE score } & & $-0.009 * * *$ \\
\hline & & $(0.000)$ \\
\hline \multirow[t]{2}{*}{ Male } & & $0.097 * * *$ \\
\hline & & $(0.007)$ \\
\hline \multirow[t]{2}{*}{ Han } & & -0.010 \\
\hline & & $(0.013)$ \\
\hline \multirow{2}{*}{$\begin{array}{l}\text { Had a white-collar job before } \\
\text { age } 60\end{array}$} & & 0.003 \\
\hline & & $(0.020)$ \\
\hline \multirow[t]{2}{*}{ Years of schooling } & & $0.004 * * *$ \\
\hline & & 0.000 \\
\hline Constant & & -0.034 \\
\hline & & $(0.178)$ \\
\hline Province dummy & No & Yes \\
\hline Observations & 19,800 & 18,459 \\
\hline
\end{tabular}


Table 7 Pension income and Food Consumption, Tobacco and Alcohol Use, Informal Care Receipt, and Health Care Access

\begin{tabular}{|c|c|c|c|c|c|c|}
\hline & \multicolumn{3}{|c|}{ Coefficient on NRPS take-up } & \multicolumn{3}{|c|}{ Coefficient on $\ln ($ NRPS income) } \\
\hline & OLS & FE & FE-IV & OLS & $\mathrm{FE}$ & FE-IV \\
\hline & $(1)$ & $(2)$ & (3) & $(4)$ & $(5)$ & $(6)$ \\
\hline \multicolumn{7}{|l|}{ Food Consumption } \\
\hline $\begin{array}{l}\text { Have sufficient financial } \\
\text { support for daily expenses }\end{array}$ & $\begin{array}{c}0.011 \\
(0.016)\end{array}$ & $\begin{array}{c}0.008 \\
(0.022)\end{array}$ & $\begin{array}{c}0.255 * * * \\
(0.055)\end{array}$ & $\begin{array}{c}0.001 \\
(0.004)\end{array}$ & $\begin{array}{c}0.002 \\
(0.005)\end{array}$ & $\begin{array}{c}0.060 * * * \\
(0.013)\end{array}$ \\
\hline Observations & 8,003 & 7,408 & 7,918 & 7,855 & 7,622 & 7,622 \\
\hline $\begin{array}{l}\text { Frequent intake of protein- } \\
\text { rich food }\end{array}$ & $\begin{array}{l}-0.028 \\
(0.019)\end{array}$ & $\begin{array}{l}-0.033 \\
(0.026)\end{array}$ & $\begin{array}{c}0.117^{* *} \\
(0.058)\end{array}$ & $\begin{array}{c}-0.011 * * \\
(0.005)\end{array}$ & $\begin{array}{c}-0.016^{* *} \\
(0.006)\end{array}$ & $\begin{array}{l}0.024^{*} \\
(0.014)\end{array}$ \\
\hline Observations & 8,005 & 7,922 & 7,922 & 7,857 & 7,626 & 7,626 \\
\hline $\begin{array}{l}\text { Frequent intake of vitamin- } \\
\text { rich food }\end{array}$ & $\begin{array}{c}0.021 \\
(0.019)\end{array}$ & $\begin{array}{l}-0.013 \\
(0.025)\end{array}$ & $\begin{array}{c}0.007 \\
(0.059)\end{array}$ & $\begin{array}{c}0.006 \\
(0.005)\end{array}$ & $\begin{array}{c}0.000 \\
(0.006)\end{array}$ & $\begin{array}{c}0.001 \\
(0.014)\end{array}$ \\
\hline Observations & 8,006 & 7,924 & 7,924 & 7,858 & 7,628 & 7,628 \\
\hline \multicolumn{7}{|l|}{ Tobacco and Alcohol Use } \\
\hline Smoking & $\begin{array}{c}0.015 \\
(0.014)\end{array}$ & $\begin{array}{c}0.012 \\
(0.013)\end{array}$ & $\begin{array}{c}0.030 \\
(0.030)\end{array}$ & $\begin{array}{c}0.003 \\
(0.003)\end{array}$ & $\begin{array}{c}0.003 \\
(0.003)\end{array}$ & $\begin{array}{c}0.005 \\
(0.007)\end{array}$ \\
\hline Observations & 7,998 & 7,908 & 7,908 & 7,850 & 7,612 & 7,612 \\
\hline Drinking & $\begin{array}{c}0.022 \\
(0.015)\end{array}$ & $\begin{array}{l}-0.022 \\
(0.016)\end{array}$ & $\begin{array}{l}-0.044 \\
(0.037)\end{array}$ & $\begin{array}{c}0.005 \\
(0.004)\end{array}$ & $\begin{array}{r}-0.007^{*} \\
(0.004)\end{array}$ & $\begin{array}{l}-0.014 \\
(0.009)\end{array}$ \\
\hline Observations & 7,977 & 7,866 & 7,866 & 7,830 & 7,572 & 7,572 \\
\hline \multicolumn{7}{|l|}{ Informal Care Receipt } \\
\hline $\begin{array}{l}\text { Hours of care received from } \\
\text { children last week }\end{array}$ & $\begin{array}{l}-1.288 \\
(1.159)\end{array}$ & $\begin{array}{c}0.607 \\
(1.189)\end{array}$ & $\begin{array}{l}3.585 \\
(2.954)\end{array}$ & $\begin{array}{l}-0.343 \\
(0.275)\end{array}$ & $\begin{array}{c}0.148 \\
(0.286)\end{array}$ & $\begin{array}{c}0.902 \\
(0.708)\end{array}$ \\
\hline Observations & 7,909 & 7,730 & 7,730 & 7,763 & 7,440 & 7,440 \\
\hline $\begin{array}{l}\text { Have someone to talk with } \\
\text { in daily life }\end{array}$ & $\begin{array}{l}0.018^{* *} \\
(0.008)\end{array}$ & $\begin{array}{c}0.014 \\
(0.010)\end{array}$ & $\begin{array}{l}0.063^{* *} \\
(0.026)\end{array}$ & $\begin{array}{l}0.005 * * * \\
(0.002)\end{array}$ & $\begin{array}{l}0.005^{*} \\
(0.003)\end{array}$ & $\begin{array}{c}0.017 * * * \\
(0.006)\end{array}$ \\
\hline Observations & 7,919 & 7,748 & 7,748 & 7,774 & 7,458 & 7,458 \\
\hline $\begin{array}{l}\text { Get help when having } \\
\text { problems/difficulties }\end{array}$ & $\begin{array}{c}0.005 \\
(0.005)\end{array}$ & $\begin{array}{c}0.017 * * \\
(0.008)\end{array}$ & $\begin{array}{l}0.034^{*} \\
(0.019)\end{array}$ & $\begin{array}{c}0.001 \\
(0.001)\end{array}$ & $\begin{array}{l}0.004 * * \\
(0.002)\end{array}$ & $\begin{array}{l}0.008 * \\
(0.004)\end{array}$ \\
\hline Observations & 7,883 & 7,676 & 7,676 & 7,738 & 7,386 & 7,386 \\
\hline \multicolumn{7}{|l|}{ Perceived Access to Health Care } \\
\hline $\begin{array}{l}\text { Get sufficient medical care } \\
\text { when sick }\end{array}$ & $\begin{array}{c}0.015 \\
(0.010)\end{array}$ & $\begin{array}{c}0.011 \\
(0.014)\end{array}$ & $\begin{array}{c}0.118 * * * \\
(0.034)\end{array}$ & $\begin{array}{c}0.005^{* *} \\
(0.002)\end{array}$ & $\begin{array}{c}0.003 \\
(0.003)\end{array}$ & $\begin{array}{c}0.028^{* * *} \\
(0.008)\end{array}$ \\
\hline Observations & 7,993 & 7,898 & 7,898 & 7,846 & 7,604 & 7,604 \\
\hline $\begin{array}{l}\text { Fail to get necessary care due } \\
\text { to costs }\end{array}$ & $\begin{array}{l}-0.002 \\
(0.006)\end{array}$ & $\begin{array}{c}0.004 \\
(0.010)\end{array}$ & $\begin{array}{c}-0.055^{* *} \\
(0.025)\end{array}$ & $\begin{array}{l}-0.001 \\
(0.001)\end{array}$ & $\begin{array}{l}-0.000 \\
(0.002)\end{array}$ & $\begin{array}{c}-0.013 * * \\
(0.006)\end{array}$ \\
\hline Observations & 7,995 & 7,902 & 7,902 & 7,847 & 7,606 & 7,606 \\
\hline
\end{tabular}

\section{Notes:}

(a) Robust standard errors are reported in parenthesis; ${ }^{*} p<0.10$, ${ }^{* *} p<0.05$, ${ }^{* * *} p<0.01$.

(b) All regressions include age, age squared/100, married, number of living children, household size, health insurance coverage, homeownership, and wave dummies. OLS estimations also include controls for gender, married status, ethnicity, years of schooling, a dummy variable for having a white-collar career before age 60 , and province dummies. 
Table 8 Pension income and Labor Supply, Leisure Activities, and Self-Perceived Relative Economic Status

\begin{tabular}{|c|c|c|c|c|c|c|}
\hline & \multicolumn{3}{|c|}{ Coefficient on NRPS enrollment } & \multicolumn{3}{|c|}{ Coefficient on $\ln ($ NRPS income) } \\
\hline & OLS & $\mathrm{FE}$ & FE-IV & OLS & $\mathrm{FE}$ & FE-IV \\
\hline & $(1)$ & $(2)$ & $(3)$ & $(4)$ & $(5)$ & $(6)$ \\
\hline \multicolumn{7}{|c|}{ Labor Supply and Leisure Activities } \\
\hline Still work & 0.011 & 0.003 & $\begin{array}{c}- \\
0.079 * * *\end{array}$ & & & $\begin{array}{c}- \\
0.018 * * *\end{array}$ \\
\hline & $(0.014)$ & $(0.008)$ & $(0.021)$ & $(0.003)$ & $(0.002)$ & $(0.005)$ \\
\hline Observations & 7,430 & 7,236 & 7,236 & 7,289 & 6,958 & 6,958 \\
\hline $\begin{array}{l}\text { Do household chores or } \\
\text { grandchild care everyday }\end{array}$ & $\begin{array}{l}0.036^{* *} \\
(0.017)\end{array}$ & $\begin{array}{c}0.030 \\
(0.021)\end{array}$ & $\begin{array}{c}0.061 \\
(0.050)\end{array}$ & $\begin{array}{l}0.009 * * \\
(0.004)\end{array}$ & $\begin{array}{l}0.008 \\
(0.005)\end{array}$ & $\begin{array}{c}0.014 \\
(0.012)\end{array}$ \\
\hline Observations & 8,010 & 7,932 & 7,932 & 7,863 & 7,638 & 7,638 \\
\hline Plant flowers or raise pets & $\begin{array}{l}0.008 \\
(0.012)\end{array}$ & $\begin{array}{c}0.014 \\
(0.015)\end{array}$ & $\begin{array}{c}0.031 \\
(0.035)\end{array}$ & $\begin{array}{c}0.002 \\
(0.003)\end{array}$ & $\begin{array}{l}0.003 \\
(0.004)\end{array}$ & $\begin{array}{c}0.006 \\
(0.008)\end{array}$ \\
\hline Observations & 8,011 & 7,934 & 7,934 & 7,863 & 7,638 & 7,638 \\
\hline Read newspapers or books & $\begin{array}{l}-0.001 \\
(0.008)\end{array}$ & $\begin{array}{c}0.004 \\
(0.009)\end{array}$ & $\begin{array}{l}0.008 \\
(0.022)\end{array}$ & $\begin{array}{c}0.000 \\
(0.002)\end{array}$ & $\begin{array}{c}0.002 \\
(0.002)\end{array}$ & $\begin{array}{c}0.001 \\
(0.005)\end{array}$ \\
\hline Observations & 8,008 & 7,928 & 7,928 & 7,861 & 7,634 & 7,634 \\
\hline Watch TV or listen to radio & $\begin{array}{l}0.044 * * \\
(0.018)\end{array}$ & $\begin{array}{l}0.052 * * \\
(0.023)\end{array}$ & $\begin{array}{l}0.095^{*} \\
(0.052)\end{array}$ & $\begin{array}{l}0.012 * * * \\
(0.005)\end{array}$ & $\begin{array}{l}0.015 * * * \\
(0.006)\end{array}$ & $\begin{array}{l}0.021^{*} \\
(0.012)\end{array}$ \\
\hline Observations & 8,011 & 7,934 & 7,934 & 7,863 & 7,638 & 7,638 \\
\hline Play cards or mah-jong & $\begin{array}{c}0.007 \\
(0.009)\end{array}$ & $\begin{array}{c}0.006 \\
(0.010)\end{array}$ & $\begin{array}{c}0.021 \\
(0.026)\end{array}$ & $\begin{array}{c}0.002 \\
(0.002)\end{array}$ & $\begin{array}{c}0.001 \\
(0.003)\end{array}$ & $\begin{array}{l}0.003 \\
(0.006)\end{array}$ \\
\hline Observations & 8,010 & 7,932 & 7,932 & 7,862 & 7,636 & 7,636 \\
\hline Participate social activities & $\begin{array}{c}0.001 \\
(0.006)\end{array}$ & $\begin{array}{c}0.007 \\
(0.007)\end{array}$ & $\begin{array}{c}0.056^{* * *} \\
(0.019)\end{array}$ & $\begin{array}{l}-0.000 \\
(0.001)\end{array}$ & $\begin{array}{c}0.001 \\
(0.002)\end{array}$ & $\begin{array}{c}0.011^{* * *} \\
(0.004)\end{array}$ \\
\hline Observations & 8,008 & 7,928 & 7,928 & 7,860 & 7,632 & 7,632 \\
\hline Leisure index & $\begin{array}{l}0.060^{* *} \\
(0.029)\end{array}$ & $\begin{array}{c}0.084 * * \\
(0.035)\end{array}$ & $\begin{array}{c}0.213^{* *} \\
(0.086)\end{array}$ & $\begin{array}{c}0.016^{* *} \\
(0.007)\end{array}$ & $\begin{array}{c}0.022 * * * \\
(0.009)\end{array}$ & $\begin{array}{l}0.043 * * \\
(0.020)\end{array}$ \\
\hline Observations & 8,012 & 7,936 & 7,936 & 7,864 & 7,640 & 7,640 \\
\hline \multicolumn{7}{|l|}{ Relative Economic Status } \\
\hline $\begin{array}{l}\text { Perceived relative economic } \\
\text { status is high }\end{array}$ & $\begin{array}{c}0.012 \\
(0.017)\end{array}$ & $\begin{array}{c}0.024 \\
(0.020)\end{array}$ & $\begin{array}{l}\text { 0.074* } \\
(0.039)\end{array}$ & $\begin{array}{l}-0.000 \\
(0.004)\end{array}$ & $\begin{array}{c}0.003 \\
(0.005)\end{array}$ & $\begin{array}{c}0.013 \\
(0.009)\end{array}$ \\
\hline Observations & 7,978 & 7,868 & 7,868 & 7,832 & 7,576 & 7,576 \\
\hline $\begin{array}{l}\text { Can make decisions on } \\
\text { household spending }\end{array}$ & $\begin{array}{c}0.022 \\
(0.015)\end{array}$ & $\begin{array}{c}0.029 \\
(0.020)\end{array}$ & $\begin{array}{c}0.001 \\
(0.046)\end{array}$ & $\begin{array}{l}0.008 * * \\
(0.004)\end{array}$ & $\begin{array}{l}0.006 \\
(0.005)\end{array}$ & $\begin{array}{l}-0.001 \\
(0.011)\end{array}$ \\
\hline Observations & 8,001 & 7,914 & 7,914 & 7,856 & 7,624 & 7,624 \\
\hline
\end{tabular}

\section{Notes:}

(a) Robust standard errors are reported in parenthesis; * $p<0.10$, ** $p<0.05$, *** $p<0.01$.

(b) All regressions include age, age squared/100, married, number of living children, household size, health insurance coverage, homeownership, and wave dummies. OLS estimations also include controls for gender, married status, ethnicity, years of schooling, a dummy variable for having a white-collar career before age 60 , and province dummies. 
Table 9 Transmission Channels (FE-IV Estimation)

\begin{tabular}{|c|c|c|c|c|c|c|c|}
\hline & $(1)$ & $(2)$ & (3) & $(4)$ & $(5)$ & $(6)$ & (7) \\
\hline & \multicolumn{7}{|c|}{ Dependent variable: No IADL limitation } \\
\hline NRPS enrollment & $\begin{array}{c}0.113^{* *} \\
(0.046)\end{array}$ & $\begin{array}{l}0.109 * * \\
(0.046)\end{array}$ & $\begin{array}{c}0.116^{* *} \\
(0.047)\end{array}$ & $\begin{array}{c}0.100 * * \\
(0.046)\end{array}$ & $\begin{array}{c}0.105^{* *} \\
(0.046)\end{array}$ & $\begin{array}{l}0.109 * * \\
(0.047)\end{array}$ & $\begin{array}{l}0.087 * \\
(0.047)\end{array}$ \\
\hline $\begin{array}{l}\text { Frequent intake of protein- } \\
\text { rich food }\end{array}$ & & $\begin{array}{c}0.030 \\
(0.021)\end{array}$ & & & & & $\begin{array}{c}0.016 \\
(0.021)\end{array}$ \\
\hline $\begin{array}{l}\text { Have someone to talk with } \\
\text { in daily life }\end{array}$ & & & $\begin{array}{l}-0.025 \\
(0.021)\end{array}$ & & & & $\begin{array}{l}-0.023 \\
(0.021)\end{array}$ \\
\hline $\begin{array}{l}\text { Get sufficient medical care } \\
\text { when sick }\end{array}$ & & & & $\begin{array}{l}0.051^{* *} \\
(0.021)\end{array}$ & & & $\begin{array}{c}0.055^{* * *} \\
(0.021)\end{array}$ \\
\hline Leisure index & & & & & $\begin{array}{c}0.040 * * * \\
(0.010)\end{array}$ & & $\begin{array}{c}0.040 * * * \\
(0.010)\end{array}$ \\
\hline $\begin{array}{l}\text { Perceived relative } \\
\text { economic status is high }\end{array}$ & & & & & & $\begin{array}{l}0.036 * * \\
(0.016)\end{array}$ & $\begin{array}{c}0.033 * * \\
(0.016)\end{array}$ \\
\hline \multirow[t]{2}{*}{ Observations } & 7,940 & 7,928 & 7,748 & 7,898 & 7,936 & 7,868 & 7,628 \\
\hline & \multicolumn{7}{|c|}{ Dependent variable: MMSE score } \\
\hline NRPS enrollment & $\begin{array}{l}2.251 * * * \\
(0.779)\end{array}$ & $\begin{array}{c}2.114 * * * \\
(0.779)\end{array}$ & $\begin{array}{l}1.926^{* *} \\
(0.757)\end{array}$ & $\begin{array}{c}2.191 * * * \\
(0.781)\end{array}$ & $\begin{array}{c}2.040 * * * \\
(0.778)\end{array}$ & $\begin{array}{c}2.212 * * * \\
(0.774)\end{array}$ & $\begin{array}{l}1.615 * * \\
(0.752)\end{array}$ \\
\hline $\begin{array}{l}\text { Frequent intake of protein- } \\
\text { rich food }\end{array}$ & & $\begin{array}{l}0.921^{* *} \\
(0.403)\end{array}$ & & & & & $\begin{array}{c}0.614 \\
(0.390)\end{array}$ \\
\hline $\begin{array}{l}\text { Have someone to talk with } \\
\text { in daily life }\end{array}$ & & & $\begin{array}{c}-4.948 * * * \\
(0.609)\end{array}$ & & & & $\begin{array}{c}-4.652 * * * \\
(0.607)\end{array}$ \\
\hline $\begin{array}{l}\text { Get sufficient medical care } \\
\text { when sick }\end{array}$ & & & & $\begin{array}{l}1.072 * * \\
(0.422)\end{array}$ & & & $\begin{array}{c}0.896 * * \\
(0.403)\end{array}$ \\
\hline Leisure index & & & & & $\begin{array}{c}1.081 * * * \\
(0.158)\end{array}$ & & $\begin{array}{c}0.865 * * * \\
(0.152)\end{array}$ \\
\hline $\begin{array}{l}\text { Perceived relative } \\
\text { economic status is high }\end{array}$ & & & & & & $\begin{array}{c}0.102 \\
(0.304)\end{array}$ & $\begin{array}{l}-0.133 \\
(0.288)\end{array}$ \\
\hline \multirow[t]{2}{*}{ Observations } & 7,930 & 7,918 & 7,744 & 7,888 & 7,926 & 7,858 & 7,624 \\
\hline & \multicolumn{7}{|c|}{ Dependent variable: Self-reported depression index } \\
\hline NRPS enrollment & $\begin{array}{c}-1.461 * * * \\
(0.419)\end{array}$ & $\begin{array}{c}-1.296 * * * \\
(0.412)\end{array}$ & $\begin{array}{c}-1.389 * * * \\
(0.419)\end{array}$ & $\begin{array}{c}-1.271 * * * \\
(0.413)\end{array}$ & $\begin{array}{c}-1.366^{* * *} \\
(0.420)\end{array}$ & $\begin{array}{c}-1.356^{* * *} \\
(0.419)\end{array}$ & $\begin{array}{c}-0.902 * * \\
(0.408)\end{array}$ \\
\hline $\begin{array}{l}\text { Frequent intake of protein- } \\
\text { rich food }\end{array}$ & & $\begin{array}{c}-1.262 * * * \\
(0.191)\end{array}$ & & & & & $\begin{array}{c}-1.120 * * * \\
(0.187)\end{array}$ \\
\hline $\begin{array}{l}\text { Have someone to talk with } \\
\text { in daily life }\end{array}$ & & & $\begin{array}{c}0.444 \\
(0.289)\end{array}$ & & & & $\begin{array}{c}0.289 \\
(0.283)\end{array}$ \\
\hline $\begin{array}{l}\text { Get sufficient medical care } \\
\text { when sick }\end{array}$ & & & & $\begin{array}{c}-1.689 * * * \\
(0.211)\end{array}$ & & & $\begin{array}{c}-1.534 * * * \\
(0.209)\end{array}$ \\
\hline Leisure index & & & & & $\begin{array}{c}-0.336 * * * \\
(0.077)\end{array}$ & & $\begin{array}{c}-0.273 * * * \\
(0.075)\end{array}$ \\
\hline $\begin{array}{l}\text { Perceived relative } \\
\text { economic status is high }\end{array}$ & & & & & & $\begin{array}{c}-0.599 * * \\
(0.236)\end{array}$ & $\begin{array}{c}-0.516^{* *} \\
(0.225)\end{array}$ \\
\hline Observations & 6,992 & 6,984 & 6,960 & 6,956 & 6,990 & 6,950 & 6,876 \\
\hline
\end{tabular}

Notes:

(a) Robust standard errors are reported in parenthesis; * $p<0.10$, ** $p<0.05$, *** $p<0.01$.

(b) All regressions include age, age squared/100, married, number of living children, household size, health insurance coverage, homeownership, and wave dummies. 
Table 10 Heterogeneous Effects by Gender and Age (FE-IV Estimation)

\begin{tabular}{|c|c|c|c|c|}
\hline & Male & Female & 85 and above & $60-85$ \\
\hline & $(1)$ & (2) & (3) & (4) \\
\hline Self-reported health is & 0.067 & -0.119 & $-0.180 * *$ & 0.088 \\
\hline good & $(0.083)$ & $(0.078)$ & $(0.083)$ & $(0.079)$ \\
\hline Observations & 3,212 & 4,714 & 3,546 & 4,380 \\
\hline \multirow[t]{2}{*}{ No IADL limitation } & 0.022 & $0.167 * * *$ & -0.029 & $0.219 * * *$ \\
\hline & $(0.071)$ & $(0.061)$ & $(0.059)$ & $(0.069)$ \\
\hline Observations & 3,218 & 4,722 & 3,556 & 4,384 \\
\hline \multirow{3}{*}{$\begin{array}{l}\text { Measured hypertension at } \\
\text { interview } \\
\text { Observations }\end{array}$} & $-0.256^{* * *}$ & $-0.169 *$ & -0.040 & $-0.331 * * *$ \\
\hline & $(0.090)$ & $(0.087)$ & $(0.095)$ & $(0.083)$ \\
\hline & 3,086 & 4,444 & 3,296 & 4,234 \\
\hline \multirow[t]{2}{*}{ Measured height } & $3.192 * * *$ & $3.680 * * *$ & $5.005 * * *$ & $2.383^{* *}$ \\
\hline & $(1.193)$ & (1.197) & $(1.496)$ & $(0.976)$ \\
\hline Observations & 3,070 & 4,276 & 3,098 & 4,248 \\
\hline \multirow[t]{2}{*}{ MMSE score } & $2.544 * *$ & $2.057 *$ & 1.726 & $2.549 * * *$ \\
\hline & $(1.036)$ & (1.138) & $(1.482)$ & $(0.755)$ \\
\hline Observations & 3,212 & 4,718 & 3,548 & 4,382 \\
\hline Cognitive function is & $0.167 * *$ & $0.191 * * *$ & $0.236 * * *$ & $0.131^{* *}$ \\
\hline good & $(0.066)$ & $(0.068)$ & $(0.081)$ & $(0.055)$ \\
\hline Observations & 3,212 & 4,718 & 3,548 & 4,382 \\
\hline Self-reported depression & $-1.461 * *$ & $-1.550 * * *$ & -0.432 & $-2.159 * * *$ \\
\hline index & $(0.598)$ & $(0.583)$ & $(0.665)$ & $(0.544)$ \\
\hline Observations & 2,986 & 4,006 & 2,748 & 4,244 \\
\hline
\end{tabular}

Notes:

(a) Robust standard errors are reported in parenthesis; * $p<0.10$, ** $p<0.05$, *** $p<0.01$.

(b) In each cell, we report the estimates for individual NRPS enrollment.

(c) All regressions include age, age squared/100, married, number of living children, household size, health insurance coverage, homeownership, and wave dummies. 
Table 11 Heterogeneous Effects by Living Arrangement and Income (FE-IV Estimation)

\begin{tabular}{|c|c|c|c|c|}
\hline & Coresidence & $\begin{array}{c}\text { Living } \\
\text { independently }\end{array}$ & $\begin{array}{c}\text { Above mean } \\
\text { HH income }\end{array}$ & $\begin{array}{c}\text { Below the mean } \\
\text { HH income }\end{array}$ \\
\hline & $(1)$ & $(2)$ & (3) & $(4)$ \\
\hline Self-reported health is good & $\begin{array}{l}-0.115 \\
(0.078)\end{array}$ & $\begin{array}{c}0.178 \\
(0.110)\end{array}$ & $\begin{array}{c}0.011 \\
(0.116)\end{array}$ & $\begin{array}{l}-0.049 \\
(0.069)\end{array}$ \\
\hline Observations & 4,322 & 2,210 & 2,242 & 5,072 \\
\hline No IADL limitation & $\begin{array}{c}0.075 \\
(0.058)\end{array}$ & $\begin{array}{l}0.177^{*} \\
(0.095)\end{array}$ & $\begin{array}{c}0.007 \\
(0.089)\end{array}$ & $\begin{array}{l}0.139 * * \\
(0.058)\end{array}$ \\
\hline Observations & 4,332 & 2,210 & 2,244 & 5,082 \\
\hline $\begin{array}{l}\text { Measured hypertension at } \\
\text { interview }\end{array}$ & $\begin{array}{c}-0.249 * * * \\
(0.072)\end{array}$ & $\begin{array}{c}-0.387 * * * \\
(0.127)\end{array}$ & $\begin{array}{l}-0.187 \\
(0.119)\end{array}$ & $\begin{array}{c}-0.239 * * * \\
(0.077)\end{array}$ \\
\hline Observations & 4,124 & 2,108 & 2,146 & 4,836 \\
\hline Measured height & $\begin{array}{c}4.031 * * * \\
(1.208)\end{array}$ & $\begin{array}{c}1.528 \\
(1.369)\end{array}$ & $\begin{array}{l}3.394 * * \\
(1.637)\end{array}$ & $\begin{array}{c}3.527 * * * \\
(1.038)\end{array}$ \\
\hline Observations & 3,912 & 2,140 & 2,056 & 4,744 \\
\hline MMSE score & $\begin{array}{c}0.939 \\
(1.172)\end{array}$ & $\begin{array}{c}3.568 * * * \\
(1.057)\end{array}$ & $\begin{array}{c}1.234 \\
(1.563)\end{array}$ & $\begin{array}{c}2.973 * * * \\
(0.950)\end{array}$ \\
\hline Observations & 4,324 & 2,210 & 2,242 & 5,076 \\
\hline Cognitive function is good & $\begin{array}{l}0.141 * * \\
(0.066)\end{array}$ & $\begin{array}{c}0.220 * * * \\
(0.081)\end{array}$ & $\begin{array}{c}0.113 \\
(0.094)\end{array}$ & $\begin{array}{c}0.207 * * * \\
(0.058)\end{array}$ \\
\hline Observations & 4,324 & 2,210 & 2,242 & 5,076 \\
\hline $\begin{array}{l}\text { Self-reported depression } \\
\text { index }\end{array}$ & $\begin{array}{c}-1.261^{* *} \\
(0.549)\end{array}$ & $\begin{array}{c}-2.267 * * * \\
(0.822)\end{array}$ & $\begin{array}{l}-1.512^{*} \\
(0.813)\end{array}$ & $\begin{array}{c}-1.454 * * * \\
(0.521)\end{array}$ \\
\hline Observations & 3,630 & 2,124 & 2,024 & 4,432 \\
\hline
\end{tabular}
Notes:

(a) Robust standard errors are reported in parenthesis; * $p<0.10$, $* * p<0.05$, ${ }^{* * *} p<0.01$.

(b) In each cell, we report the estimates for individual NRPS enrollment.

(c) All regressions include age, age squared/100, married, number of living children, household size, health insurance coverage, homeownership, and wave dummies. 
Table A1 Number of Respondents

\begin{tabular}{lcc}
\hline Main analysis & Number excluded & Number remaining \\
\hline CLHLS 2008/09 & & 16950 \\
Rural elderly aged 60 and above & 6755 & 10195 \\
Exclude respondents with missing values for social pension & 225 & 9970 \\
Exclude respondents with any other types of pension, including & 1287 & $\mathbf{8 6 8 3}$ \\
& \\
\hline Respondents lost to follow-up in 2011/12 survey & 1168 \\
Respondents deceased before 2011/12 survey & 3362 \\
$\quad$ Participated in NRPS & $270(8.03 \%)$ \\
$\quad$ Did not participate in NRPS & $3092(91.97 \%)$ \\
Respondents re-interviewed in 2011/12 survey & $\mathbf{4 1 5 3}$ \\
$\quad$ Participated in NRPS & & $907(21.84 \%)$ \\
Did not participate in NRPS & $3246(77.45 \%)$ \\
\hline
\end{tabular}


Table A2 FE-IV Estimations for Health Outcomes of the Elderly

\begin{tabular}{|c|c|c|c|c|c|c|c|c|c|c|c|c|c|c|c|c|}
\hline & \multicolumn{2}{|c|}{ First stage estimates } & \multirow{2}{*}{\multicolumn{2}{|c|}{ Self-reported health is good }} & \multirow{2}{*}{\multicolumn{2}{|c|}{ No IADL limitation }} & \multirow{2}{*}{\multicolumn{2}{|c|}{$\begin{array}{c}\text { Measured hypertension at } \\
\text { interview }\end{array}$}} & \multirow{2}{*}{\multicolumn{2}{|c|}{ Measured height }} & \multirow{2}{*}{\multicolumn{2}{|c|}{ MMSE score }} & \multirow{2}{*}{\multicolumn{2}{|c|}{ Cognitive function is good }} & \multirow{2}{*}{\multicolumn{2}{|c|}{$\begin{array}{l}\text { Self-reported depression } \\
\text { index }\end{array}$}} \\
\hline & \multirow{2}{*}{$\frac{\text { NRPS take-up }}{(1)}$} & \multirow{2}{*}{$\begin{array}{c}\begin{array}{c}\ln (\mathrm{NRPS} \\
\text { income })\end{array} \\
\text { (2) }\end{array}$} & & & & & & & & & & & & & & \\
\hline & & & (3) & (4) & (5) & (6) & (7) & (8) & (9) & (10) & (11) & (12) & (13) & (14) & (15) & (16) \\
\hline \multirow[t]{2}{*}{ NRPS take-up } & & & -0.034 & & $0.113 * *$ & & $-0.211^{* * *}$ & & $3.491 * * *$ & & $2.251^{* * *}$ & & $0.178^{* * *}$ & & $-1.461 * * *$ & \\
\hline & & & $(0.057)$ & & $(0.046)$ & & $(0.062)$ & & $(0.846)$ & & $(0.779)$ & & $(0.047)$ & & $(0.419)$ & \\
\hline \multirow{2}{*}{$\ln ($ NRPS income) } & & & & -0.009 & & $0.024 * *$ & & $-0.054 * * *$ & & $0.798^{* * * *}$ & & $0.572^{* * * *}$ & & $0.042^{* * * *}$ & & $-0.301 * * *$ \\
\hline & & & & $(0.013)$ & & $(0.011)$ & & $(0.015)$ & & $(0.198)$ & & $(0.182)$ & & $(0.011)$ & & $(0.099)$ \\
\hline Program duration in & $0.021 * * *$ & $0.089 * * *$ & & & & & & & & & & & & & & \\
\hline the county (months) & $(0.001)$ & $(0.003)$ & & & & & & & & & & & & & & \\
\hline \multirow[t]{2}{*}{ Age } & $-0.066 * * *$ & $-0.292 * * *$ & 0.042 & 0.048 & $-0.130^{* * *}$ & $-0.132 * * *$ & 0.028 & 0.040 & 0.709 & 0.714 & $1.095 * *$ & $1.040 * *$ & $0.063 * *$ & $0.054^{*}$ & 0.359 & 0.293 \\
\hline & $(0.023)$ & $(0.093)$ & $(0.037)$ & $(0.038)$ & $(0.025)$ & $(0.025)$ & $(0.040)$ & $(0.042)$ & $(0.636)$ & $(0.657)$ & $(0.497)$ & $(0.511)$ & $(0.027)$ & $(0.028)$ & $(0.241)$ & $(0.246)$ \\
\hline \multirow[t]{2}{*}{ Age squared/100 } & -0.004 & -0.033 & 0.002 & -0.005 & $0.068^{* * *}$ & $0.069^{* * *}$ & $-0.038 * *$ & $-0.041^{* *}$ & $-0.796 * * *$ & $-0.783^{* * *}$ & $-0.623 * * *$ & $-0.629 * * *$ & $-0.026^{* *}$ & $-0.025^{* *}$ & $-0.426 * * *$ & $-0.427 * * *$ \\
\hline & $(0.009)$ & $(0.036)$ & $(0.015)$ & $(0.015)$ & $(0.010)$ & $(0.010)$ & $(0.016)$ & $(0.017)$ & $(0.264)$ & $(0.271)$ & $(0.220)$ & $(0.226)$ & $(0.011)$ & $(0.012)$ & $(0.107)$ & $(0.110)$ \\
\hline \multirow[t]{2}{*}{ Married } & 0.021 & 0.067 & 0.054 & $0.058^{*}$ & 0.027 & 0.022 & 0.005 & 0.009 & -0.330 & -0.150 & 0.251 & 0.151 & 0.003 & -0.003 & $-0.383^{*}$ & $-0.444 *$ \\
\hline & $(0.017)$ & $(0.069)$ & $(0.033)$ & $(0.034)$ & $(0.027)$ & $(0.027)$ & $(0.038)$ & $(0.039)$ & $(0.457)$ & $(0.453)$ & $(0.457)$ & $(0.465)$ & $(0.031)$ & $(0.031)$ & $(0.225)$ & $(0.227)$ \\
\hline Number of living & -0.007 & -0.015 & $0.063 * *$ & $0.068^{* * *}$ & 0.008 & 0.009 & $-0.054 * *$ & $-0.052^{*}$ & 0.470 & 0.480 & 0.054 & 0.068 & 0.024 & 0.023 & -0.126 & -0.113 \\
\hline children & $(0.018)$ & $(0.073)$ & $(0.028)$ & $(0.028)$ & $(0.024)$ & $(0.025)$ & $(0.026)$ & $(0.027)$ & $(0.375)$ & $(0.380)$ & $(0.383)$ & $(0.395)$ & $(0.020)$ & $(0.021)$ & $(0.186)$ & $(0.188)$ \\
\hline \multirow[t]{2}{*}{ Household size } & 0.003 & 0.017 & 0.003 & 0.003 & -0.004 & -0.004 & -0.003 & -0.005 & -0.062 & -0.045 & -0.078 & -0.080 & $-0.009 * *$ & $-0.010^{* *}$ & $-0.114 * * *$ & $-0.112^{* * *}$ \\
\hline & $(0.003)$ & $(0.011)$ & $(0.005)$ & $(0.005)$ & $(0.004)$ & $(0.004)$ & $(0.005)$ & $(0.005)$ & $(0.079)$ & $(0.080)$ & $(0.070)$ & $(0.071)$ & $(0.004)$ & $(0.004)$ & $(0.035)$ & $(0.035)$ \\
\hline \multirow[t]{2}{*}{ Owns the home } & 0.009 & 0.053 & -0.017 & -0.020 & $0.029^{*}$ & $0.031 * *$ & $-0.042^{*}$ & $-0.039^{*}$ & $0.559^{*}$ & $0.512^{*}$ & $0.793 * * *$ & $0.796 * * *$ & $0.047^{* * *}$ & $0.048^{* * *}$ & 0.136 & 0.203 \\
\hline & $(0.010)$ & $(0.042)$ & $(0.019)$ & $(0.019)$ & $(0.015)$ & $(0.016)$ & $(0.022)$ & $(0.023)$ & $(0.304)$ & $(0.309)$ & $(0.263)$ & $(0.269)$ & $(0.016)$ & $(0.016)$ & $(0.132)$ & (0.134) \\
\hline Have health & $-0.033 * * *$ & $-0.129 * * *$ & -0.002 & 0.003 & -0.025 & -0.024 & 0.021 & 0.021 & 0.371 & 0.332 & $1.668^{* * *}$ & $1.700^{* * *}$ & $0.077^{* * *}$ & $0.079 * * *$ & 0.020 & 0.032 \\
\hline insurance & $(0.011)$ & $(0.044)$ & $(0.020)$ & $(0.021)$ & $(0.015)$ & $(0.016)$ & $(0.020)$ & $(0.021)$ & $(0.346)$ & $(0.350)$ & $(0.300)$ & $(0.307)$ & $(0.018)$ & $(0.018)$ & $(0.145)$ & (0.148) \\
\hline \multirow[t]{2}{*}{ Wave 2011/12 } & $0.274 * * *$ & $1.150^{* * *}$ & $-0.206 * *$ & $-0.185 * *$ & -0.077 & -0.067 & $0.187^{*}$ & $0.167^{*}$ & -1.416 & -1.447 & $-2.263 *$ & -2.035 & $-0.176 * *$ & $-0.148 * *$ & $0.987^{*}$ & $1.103^{*}$ \\
\hline & $(0.055)$ & $(0.223)$ & $(0.085)$ & $(0.087)$ & $(0.059)$ & $(0.061)$ & $(0.096)$ & $(0.100)$ & $(1.387)$ & (1.425) & $(1.218)$ & (1.247) & $(0.068)$ & $(0.070)$ & $(0.574)$ & $(0.583)$ \\
\hline Weak instrument test & $779.78^{* * *}$ & $757.16^{* * *}$ & & & & & & & & & & & & & & \\
\hline Observations & 7,940 & 7,644 & 7,926 & 7,630 & 7,940 & 7,644 & 7,530 & 7,252 & 7,346 & 7,082 & 7,930 & 7,634 & 7,930 & 7,634 & 6,992 & 6,740 \\
\hline
\end{tabular}


Table A3 2008/09 Characteristics by Attrition Status in 2011/12

\begin{tabular}{|c|c|c|c|c|c|c|}
\hline \multirow{3}{*}{ The elderly sample in wave $2008 / 09$} & \multirow{2}{*}{$\begin{array}{c}\text { Full sample } \\
\quad N=8,683\end{array}$} & \multirow{2}{*}{$\begin{array}{l}\text { Attritors } \\
\mathrm{N}=1,168\end{array}$} & \multicolumn{3}{|c|}{ Non-Attritors } & \multirow{3}{*}{ Diff. (3)-(2) } \\
\hline & & & $\begin{array}{c}\text { All } \\
N=7,515\end{array}$ & $\begin{array}{c}\text { Alive } \\
N=4,153\end{array}$ & $\begin{array}{c}\text { Deceased } \\
N=3,362\end{array}$ & \\
\hline & (1) & (2) & (3) & (4) & (5) & \\
\hline \multirow[t]{2}{*}{ Self-reported health is good } & 0.406 & 0.364 & 0.413 & 0.474 & 0.337 & $0.049 * * *$ \\
\hline & 0.491 & 0.481 & 0.492 & 0.499 & 0.473 & \\
\hline \multirow[t]{2}{*}{ No IADL limitation } & 0.282 & 0.283 & 0.282 & 0.420 & 0.112 & 0.000 \\
\hline & 0.450 & 0.450 & 0.450 & 0.494 & 0.316 & \\
\hline \multirow[t]{2}{*}{ Measured hypertension at interview } & 0.410 & 0.388 & 0.414 & 0.429 & 0.395 & 0.026 \\
\hline & 0.492 & 0.488 & 0.493 & 0.495 & 0.489 & \\
\hline \multirow[t]{2}{*}{ Measured height } & 155.132 & 156.469 & 154.923 & 155.892 & 153.675 & $-1.546^{* * *}$ \\
\hline & 10.148 & 10.046 & 10.148 & 9.684 & 10.588 & \\
\hline \multirow[t]{2}{*}{ MMSE score } & 19.581 & 19.960 & 19.522 & 23.025 & 15.194 & -0.438 \\
\hline & 10.474 & 10.291 & 10.502 & 8.553 & 11.059 & \\
\hline \multirow[t]{2}{*}{ Cognitive function is good } & 0.508 & 0.524 & 0.506 & 0.658 & 0.317 & -0.018 \\
\hline & 0.500 & 0.500 & 0.500 & 0.474 & 0.466 & \\
\hline \multirow[t]{2}{*}{ Self-reported depression index } & 6.076 & 6.550 & 6.001 & 5.755 & 6.371 & $-0.549 * * *$ \\
\hline & 3.356 & 3.485 & 3.329 & 3.249 & 3.414 & \\
\hline \multirow[t]{2}{*}{ Age } & 87.742 & 87.303 & 87.810 & 82.997 & 93.756 & 0.507 \\
\hline & 11.733 & 13.279 & 11.474 & 11.163 & 8.740 & \\
\hline \multirow[t]{2}{*}{ Male } & 0.384 & 0.386 & 0.384 & 0.411 & 0.351 & -0.002 \\
\hline & 0.487 & 0.487 & 0.486 & 0.492 & 0.477 & \\
\hline Had a white-collar career before age & 0.013 & 0.021 & 0.012 & 0.012 & 0.012 & $-0.009^{* *}$ \\
\hline 60 & 0.112 & 0.142 & 0.107 & 0.107 & 0.107 & \\
\hline \multirow[t]{2}{*}{ Han } & 0.922 & 0.953 & 0.917 & 0.920 & 0.914 & -0.036 \\
\hline & 0.268 & 0.212 & 0.276 & 0.272 & 0.280 & \\
\hline \multirow[t]{2}{*}{ Married } & 0.273 & 0.251 & 0.276 & 0.380 & 0.148 & $0.025^{*}$ \\
\hline & 0.445 & 0.434 & 0.447 & 0.485 & 0.356 & \\
\hline \multirow[t]{2}{*}{ Years of schooling } & 1.252 & 1.327 & 1.241 & 1.507 & 0.912 & -0.086 \\
\hline & 2.453 & 2.544 & 2.439 & 2.584 & 2.202 & \\
\hline \multirow[t]{2}{*}{ Household size } & 3.335 & 3.185 & 3.358 & 3.198 & 3.556 & $0.173 * * *$ \\
\hline & 1.962 & 1.818 & 1.983 & 1.950 & 2.005 & \\
\hline \multirow[t]{2}{*}{ Owns the home } & 0.388 & 0.442 & 0.380 & 0.473 & 0.264 & $-0.062 * * *$ \\
\hline & 0.487 & 0.497 & 0.485 & 0.499 & 0.441 & \\
\hline \multirow[t]{2}{*}{ Number of living children } & 3.806 & 3.585 & 3.840 & 4.015 & 3.626 & $0.255^{* * *}$ \\
\hline & 1.826 & 1.741 & 1.837 & 1.795 & 1.866 & \\
\hline \multirow[t]{2}{*}{ Have health insurance } & 0.730 & 0.624 & 0.746 & 0.767 & 0.720 & $0.122 * * *$ \\
\hline & 0.444 & 0.485 & 0.435 & 0.423 & 0.449 & \\
\hline
\end{tabular}

Notes: $t$-test was applied to test the significance of the difference between columns (3) and (2). ${ }^{* * *} p<0.01,{ }^{* *} p<0.05,{ }^{*} p<0.1$. 
Table A4 Difference between the Attrited and Non-Attrited Samples

\begin{tabular}{|c|c|c|c|c|c|c|c|c|c|c|c|c|}
\hline \multirow[t]{2}{*}{ Dependent variable: } & \multicolumn{2}{|c|}{$\begin{array}{l}\text { Self-reported health is } \\
\text { good }\end{array}$} & \multicolumn{2}{|c|}{ No IADL limitation } & \multicolumn{2}{|c|}{$\begin{array}{c}\text { Measured Hypertension at } \\
\text { interview }\end{array}$} & \multicolumn{2}{|c|}{ Measured height } & \multicolumn{2}{|c|}{ MMSE score } & \multicolumn{2}{|c|}{$\begin{array}{c}\text { Self-reported } \\
\text { depression index }\end{array}$} \\
\hline & Coeff. & S.E. & Coeff. & S.E. & Coeff. & S.E. & Coeff. & S.E. & Coeff. & S.E. & Coeff. & S.E. \\
\hline Age & -0.025 & $(0.020)$ & $-0.233 * * *$ & $(0.033)$ & $0.050^{* *}$ & $(0.022)$ & $-0.319^{* * *}$ & $(0.116)$ & $0.774 * * *$ & $(0.123)$ & $0.453 * * *$ & $(0.052)$ \\
\hline Age squared/100 & 0.009 & $(0.012)$ & $0.089 * * *$ & $(0.020)$ & $-0.031 * *$ & $(0.012)$ & $0.117^{*}$ & $(0.068)$ & $-0.696^{* * *}$ & $(0.073)$ & $-0.260 * * *$ & $(0.030)$ \\
\hline Married & -0.052 & $(0.042)$ & 0.059 & $(0.047)$ & -0.071 & $(0.044)$ & $0.464 * *$ & $(0.236)$ & 0.241 & $(0.241)$ & $-0.461 * * *$ & $(0.103)$ \\
\hline Number of living children & $0.020^{* *}$ & $(0.008)$ & 0.015 & $(0.011)$ & 0.014 & $(0.009)$ & 0.043 & $(0.051)$ & $0.111 *$ & $(0.056)$ & $-0.076^{* * *}$ & $(0.023)$ \\
\hline Family size & $0.023 * * *$ & $(0.008)$ & -0.015 & $(0.011)$ & -0.010 & $(0.009)$ & 0.017 & $(0.049)$ & $-0.101^{*}$ & $(0.054)$ & $-0.197 * * *$ & $(0.021)$ \\
\hline Owns an apartment & 0.017 & $(0.037)$ & $0.224 * * *$ & $(0.045)$ & -0.041 & $(0.040)$ & $0.426^{*}$ & $(0.219)$ & $1.210^{* * *}$ & $(0.233)$ & $0.205^{* *}$ & $(0.096)$ \\
\hline Having some health insurance & $0.133 * * *$ & $(0.038)$ & $0.112 * *$ & $(0.049)$ & $0.066^{*}$ & $(0.040)$ & $-0.445^{*}$ & $(0.233)$ & $1.718 * * *$ & $(0.257)$ & $-0.415^{* * *}$ & $(0.103)$ \\
\hline Male & $0.074^{* *}$ & $(0.036)$ & $0.418 * * *$ & $(0.044)$ & $-0.107 * * *$ & $(0.038)$ & $11.315^{* * *}$ & $(0.211)$ & $1.517 * * *$ & $(0.225)$ & $-0.292 * * *$ & $(0.091)$ \\
\hline Han & $-0.147 * *$ & $(0.062)$ & -0.072 & $(0.079)$ & -0.037 & $(0.066)$ & -0.240 & $(0.339)$ & $-1.097 * * *$ & $(0.378)$ & -0.183 & $(0.148)$ \\
\hline Had a white-collar job before age 60 & -0.170 & $(0.143)$ & -0.092 & $(0.163)$ & 0.048 & $(0.143)$ & $1.853^{* *}$ & $(0.736)$ & 0.054 & $(0.800)$ & $0.606^{*}$ & $(0.347)$ \\
\hline Years of schooling & $0.016^{* *}$ & $(0.007)$ & 0.013 & $(0.008)$ & 0.006 & $(0.008)$ & $0.117 * * *$ & $(0.040)$ & $0.264 * * *$ & $(0.042)$ & $-0.052 * * *$ & $(0.018)$ \\
\hline Constant & $1.587^{*}$ & $(0.904)$ & $11.885^{* * *}$ & $(1.424)$ & -1.559 & $(0.949)$ & $174.007 * * *$ & $(5.025)$ & 5.216 & $(5.284)$ & $-13.730^{* * *}$ & $(2.262)$ \\
\hline Attrition (loss to follow-up) & 2.493 & $(2.159)$ & $-6.221 * *$ & $(3.100)$ & -0.466 & $(2.259)$ & -17.013 & $(11.643)$ & 0.556 & $(12.264)$ & 1.838 & $(4.982)$ \\
\hline Attrition $\times$ Age & -0.045 & $(0.048)$ & $0.161^{* *}$ & $(0.074)$ & 0.002 & $(0.051)$ & 0.275 & $(0.263)$ & -0.127 & $(0.286)$ & -0.121 & $(0.115)$ \\
\hline Attrition $\times$ Age squared $/ 100$ & 0.023 & $(0.028)$ & $-0.098 * *$ & $(0.044)$ & -0.003 & $(0.030)$ & -0.172 & $(0.155)$ & 0.063 & $(0.172)$ & 0.080 & $(0.068)$ \\
\hline Attrition $\times$ Married & -0.067 & $(0.130)$ & 0.060 & $(0.149)$ & -0.060 & $(0.139)$ & 0.049 & $(0.782)$ & 0.517 & $(0.670)$ & -0.424 & $(0.290)$ \\
\hline Attrition $\times$ Number of living children & $0.047^{*}$ & $(0.026)$ & -0.040 & $(0.035)$ & -0.007 & $(0.027)$ & -0.096 & $(0.142)$ & 0.046 & $(0.160)$ & -0.018 & $(0.065)$ \\
\hline Attrition $\times$ Family size & -0.031 & $(0.025)$ & -0.056 & $(0.035)$ & $-0.075^{* * *}$ & $(0.027)$ & $0.234^{*}$ & $(0.136)$ & -0.187 & $(0.153)$ & 0.040 & $(0.061)$ \\
\hline Attrition $\times$ Owns an apartment & -0.141 & $(0.110)$ & -0.079 & $(0.136)$ & $-0.235^{* *}$ & $(0.114)$ & 0.962 & $(0.619)$ & $-1.477 * *$ & $(0.682)$ & $0.595 * *$ & $(0.274)$ \\
\hline Attrition $\times$ Having health insurance & 0.062 & $(0.108)$ & -0.081 & $(0.141)$ & 0.047 & $(0.111)$ & 0.212 & $(0.604)$ & -0.148 & $(0.666)$ & -0.102 & $(0.276)$ \\
\hline Attrition $\times$ Male & -0.043 & $(0.098)$ & $-0.219^{*}$ & $(0.124)$ & 0.166 & $(0.102)$ & -0.825 & $(0.517)$ & -0.329 & $(0.571)$ & 0.023 & $(0.229)$ \\
\hline Attrition $\times$ Han & 0.080 & $(0.219)$ & 0.175 & $(0.300)$ & -0.131 & $(0.248)$ & 1.398 & $(1.066)$ & $3.017^{* *}$ & $(1.180)$ & $1.055^{* *}$ & $(0.486)$ \\
\hline Attrition $\times$ Had a white-collar job before age 60 & -0.352 & $(0.329)$ & -0.017 & $(0.336)$ & -0.316 & $(0.337)$ & -1.186 & $(2.007)$ & -1.866 & $(2.069)$ & 0.573 & $(0.669)$ \\
\hline Attrition $\times$ Years of schooling & 0.018 & $(0.021)$ & $0.054 * *$ & $(0.026)$ & 0.014 & $(0.022)$ & 0.028 & $(0.110)$ & -0.029 & $(0.121)$ & -0.026 & $(0.048)$ \\
\hline Attrition $\times$ province dummies & Yes & & Yes & & Yes & & Yes & & Yes & & Yes & \\
\hline Province dummies & Yes & & Yes & & Yes & & Yes & & Yes & & Yes & \\
\hline Observations & 8,447 & & 8,427 & & 7,948 & & 8,191 & & 8,453 & & 7,259 & \\
\hline $\begin{array}{l}\text { F-statistic for test on the joint effect of attrition } \\
\text { constant and coefficient estimates }\end{array}$ & $F=8.66$ & $P=0.372$ & $F=8.93$ & $P=0.349$ & $F=11.35$ & $P=0.183$ & $F=1.17$ & $P=0.312$ & $F=1.09$ & $P=0.370$ & $F=11.35$ & $P=0.1825$ \\
\hline all coefficient estimates but no constant & $F=8.37$ & $P=0.301$ & $F=8.87$ & $P=0.262$ & $F=10.46$ & $P=0.164$ & $F=0.98$ & $P=0.440$ & $F=0.82$ & $P=0.571$ & $F=10.46$ & $P=0.164$ \\
\hline
\end{tabular}

